\title{
ARTICLE
}

\section{Cyclin D2 overexpression drives B1a-derived MCL-like lymphoma in mice}

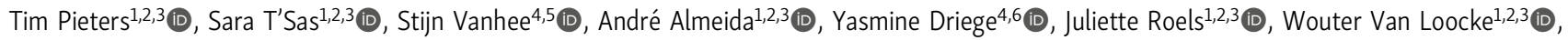 \\ Willem Daneels ${ }^{3,5,7}$ (D), Mathijs Baens ${ }^{8}$ (D) Arnaud Marchand ${ }^{8}$ (D) Maaike Van Trimpont ${ }^{1,2,3}$ (D) Filip Matthijssens $s^{1,2,3}$ (D), Julie Morscio ${ }^{1,2,3}$ (D),

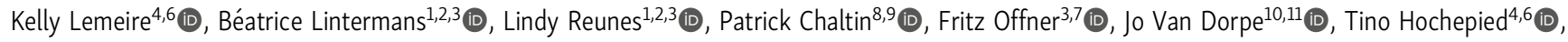 \\ Geert Berx ${ }^{3,4,6}$ (D), Rudi Beyaert ${ }^{4,6}$ (D), Jens Staal ${ }^{4,6}$ (D), Pieter Van Vlierberghe ${ }^{1,2,3 *}$ (D), and Steven Goossens $\mathbf{S}^{1,2,3,10 *}$ (D)
}

Mantle cell lymphoma (MCL) is an aggressive B cell lymphoma with poor long-term overall survival. Currently, MCL research and development of potential cures is hampered by the lack of good in vivo models. MCL is characterized by recurrent translocations of CCND1 or CCND2, resulting in overexpression of the cell cycle regulators cyclin D1 or D2, respectively. Here, we show, for the first time, that hematopoiesis-specific activation of cyclin D2 is sufficient to drive murine MCL-like lymphoma development. Furthermore, we demonstrate that cyclin D2 overexpression can synergize with loss of p53 to form aggressive and transplantable MCL-like lymphomas. Strikingly, cyclin D2-driven lymphomas display transcriptional, immunophenotypic, and functional similarities with Bla B cells. These MCL-like lymphomas have Bla-specific B cell receptors (BCRs), show elevated BCR and NF-KB pathway activation, and display increased MALT1 protease activity. Finally, we provide preclinical evidence that inhibition of MALT1 protease activity, which is essential for the development of early life-derived Bla cells, can be an effective therapeutic strategy to treat MCL.

\section{Introduction}

Mantle cell lymphoma (MCL) is a highly aggressive B cell lymphoma that accounts for $6 \%$ of all non-Hodgkin lymphomas and is characterized by abnormal proliferation of mature antigennaive B lymphocytes (Campo et al., 1999; Jares et al., 2012). Despite recent advances in patient risk stratification, MCL remains incurable due to frequent relapses and resistance to therapy (Campo and Rule, 2015). Constitutive activation of D-type cyclins in B cell progenitors has been considered as a genetic hallmark of human MCL. Additional secondary mutations, such as loss of the tumor suppressor TP53 (Beà et al., 2013; Greiner et al., 2006; Nadeu et al., 2020), cooperate during oncogenic transformation. Two distinct molecular subtypes have been described that differ in their clinicobiological behavior (Beekman et al., 2018; Fernàndez et al., 2010). Conventional MCL is the most common subtype, characterized by high SOX11 expression and a low number of IGHV mutations. These conventional nodal MCLs are derived from naive mature $B$ cells that reside in the mantle zone surrounding the germinal centers and display a poor overall survival, often with dissemination throughout the body and infiltration in the liver and the gastrointestinal tract (Jares et al., 2007). The second molecular subtype, the leukemic nonnodal MCL, is SOX11 negative, follows an indolent clinical course, and is derived from memory-like B cells that are germinal center experienced and, as such, harbor IGHV mutations.

Mammalian cells use specific cyclin-dependent kinase (CDK) complexes to regulate their passage through the cell cycle. Three D-type cyclins, namely cyclins D1, D2, and D3 (encoded by CCND1, CCND2, and CCND3), have been described and bind $\mathrm{CDK} 4 / 6$. At $\mathrm{G}_{1} / \mathrm{S}$ phase transition, the activation of cyclin DCDK4/6 complexes leads to the activation of E2F transcription factors and progression through the cell cycle. Gene function studies have demonstrated that D-type cyclins have partially overlapping and redundant roles in cell cycle control (Musgrove et al., 2011; Sherr and Roberts, 2004). Because D-type cyclins

\footnotetext{
${ }^{1}$ Department of Biomolecular Medicine, Ghent University, Ghent, Belgium; ${ }^{2}$ Center for Medical Genetics, Ghent University and University Hospital, Ghent, Belgium; ${ }^{3}$ Cancer Research Institute Ghent, Ghent, Belgium; ${ }^{4}$ Center for Inflammation Research, Flemish Institute for Biotechnology, Ghent, Belgium; ${ }^{5}$ Department of Internal Medicine and Pediatrics, Ghent University, Ghent, Belgium; ${ }^{6}$ Department of Biomedical Molecular Biology, Ghent University, Ghent, Belgium; ${ }^{7}$ Department of Hematology, Ghent University Hospital, Ghent, Belgium; ${ }^{8}$ Center for Innovation and Stimulation of Drug Discovery Leuven, Leuven, Belgium; ${ }^{9}$ Center for Drug Design and Discovery, Catholic University of Leuven, Leuven, Belgium; ${ }^{10}$ Department of Diagnostic Sciences, Ghent University, Ghent, Belgium; ${ }^{11}$ Department of Pathology, Ghent University Hospital, Ghent, Belgium.

*P. Van Vlierberghe and S. Goossens contributed equally to this paper; Correspondence to Pieter Van Vlierberghe: pieter.vanvlierberghe@ugent.be; Steven Goossens: steven.goossens@ugent.be.
}

(c) 2021 Pieters et al. This article is distributed under the terms of an Attribution-Noncommercial-Share Alike-No Mirror Sites license for the first six months after the publication date (see http://www.rupress.org/terms/). After six months it is available under a Creative Commons License (Attribution-Noncommercial-Share Alike 4.0 International license, as described at https://creativecommons.org/licenses/by-nc-sa/4.0/). 
share a similar structure and function, they could be equally potent in driving cancer upon aberrant activation.

The majority of MCL patients carry a $t(11 ; 14)(q 13 ; q 32)$ translocation that leads to the juxtaposition of the CCND1 gene to the Ig locus, resulting in cyclin D1 overexpression. Approximately $10-15 \%$ of MCLs lack the typical $t(11 ; 14)$ but have similar clinical, pathological, and genetic features. These so-called cyclin D1-negative MCLs display increased expression of either cyclin D2 or cyclin D3 (Fu et al., 2005; Mozos et al., 2009). Recurrent translocations involving CCND2 and the Ig heavy and light chain loci have been identified in such cases (Martín-Garcia et al., 2019; Salaverria et al., 2013) and were acknowledged in the recent World Health Organization classification of lymphoid neoplasms (Swerdlow et al., 2016). In addition, cryptic insertions that result in the integration of Ig light chain enhancers near CCND2 or CCND3 have also been observed as another genetic mechanism for cyclin D2 or cyclin D3 overexpression (Martín-Garcia et al., 2019). Therefore, accumulating genetic evidence suggests that, next to cyclin D1, also other cyclin D family members might play an oncogenic role in the pathobiology of MCL.

Although translocations involving CCND1 are frequent, mouse models with elevated expression of cyclin D1 alone do not spontaneously develop MCL (Bodrug et al., 1994; Lovec et al., 1994), except upon mitogenic stimulation in aged mice (Smith et al., 2006) or upon depletion of the proapoptotic Bcl-2 family protein BIM (Katz et al., 2014). Currently, fully penetrant spontaneous MCL mouse models are lacking and would be of great importance to enable preclinical in vivo drug screening and pave the way for novel and better therapeutic strategies for the treatment of MCL.

Here, we report a novel spontaneous in vivo cyclin D2-driven MCL-like mouse model that faithfully recapitulates most pathophysiological and molecular features of human MCL. We found that $C$ cnd2-driven murine MCL-like lymphomas are reminiscent of early life-derived Bla cells at the transcription and functional levels and express BCRs that bind self-antigens, providing constitutive activation of the BCR pathway. This could support them in transforming from self-renewing cells into malignant MCL-like lymphomas. In addition, we found that the oncogenic transformation driven by $\mathrm{C} c n d 2$ was accelerated in the absence of the tumor suppressor p53. Indeed, in a p53-deficient context, cyclin D2 overexpression specifically stimulates oncogenic transformation of $\mathrm{CD}_{19}{ }^{+} \mathrm{CD} 5^{+} \mathrm{CD} 23^{-} \mathrm{Bla}$ cells, which resemble the immunophenotype of human MCL patients. Like Bla cells, our Ccnd2-driven murine MCL-like lymphomas have enhanced $\mathrm{NF}-\mathrm{\kappa B}$ pathway activation with increased mucosa-associated lymphoid tissue translocation protein 1 (MALT1) protease activity. Finally, we demonstrate that these Bla/MCL-like lymphomas are transplantable and druggable, such as by inhibition of MALT1 protease activity, showing that our model is particularly suited for preclinical evaluation of novel therapeutic strategies.

\section{Results}

Hematopoietic cyclin D2 expression drives MCL-like lymphoma in mice

To evaluate whether cyclin D2 could act as a bona fide MCL oncogene, we developed a conditional Ccnd2 overexpression mouse model (Fig. $1 \mathrm{~A}$ ) using a previously optimized pipeline for targeting the Rosa26 (R26) locus (Fig. S1 A; Pieters et al., 2019). R26-Ccnd2 mice were crossed to Vav-iCre mice (de Boer et al., 2003 ) to enable biallelic R26-driven overexpression of cyclin D2 in the entire hematopoietic system, including B cells (Fig. S1, $\mathrm{C}$ and D). We monitored an aging cohort of R26-Ccnd2 ${ }^{\text {tg/tg; }}$; Vav-iCre ${ }^{\text {tg/+ }}$ (hereafter named Cond2 ${ }^{\text {Vav }}$ ) mice and found that 5 (29\%) of 17 animals spontaneously developed lymphomas (Figs. $1 \mathrm{~B}$ and S1 E). The obtained Cond2 ${ }^{\mathrm{Vav}}$ tumors were composed of monomorphic, small-sized cells with irregular hyperchromatic nuclei (Fig. $1 \mathrm{C}$ ), displayed an MCL-like $\mathrm{CD} 19^{+} \mathrm{CD} 2 \mathrm{O}^{+} \mathrm{CD} 5^{+} \mathrm{CD} 23^{-}$ immunophenotype (Fig. 1 D; Jares et al., 2007), and expressed the MCL marker Soxl1 (Fig. 1 E). In line with human conventional MCLs, which are mature but naive lymphomas that express IgM and lack expression of the immature Tdt marker, $\mathrm{Ccnd2}^{\mathrm{Vav}}$ mice were also IgM ${ }^{+} \mathrm{Tdt}^{-}$(Fig. $1 \mathrm{D}$ ). Lymphoma-bearing $\mathrm{Ccnd2}^{\text {Vav }}$ mice had nodules or infiltrates of proliferating $\mathrm{B}^{2} 2 \mathrm{O}^{+} \mathrm{KI} 67^{+}$neoplastic $B$ cells in their gastrointestinal tract, liver, spleen, and mediastinal lymph nodes (Fig. 1, F and G). Three Ccnd2 ${ }^{\mathrm{Vav}}$ mice developed severe splenomegaly (Fig. S1 F) with a profound loss of the normal parenchymal architecture, while white pulp compartments were obscured by a dense proliferation of small to medium-sized lymphoid cells. Next, we performed whole-exome sequencing (WES) on four Ccnd2-driven B cell lymphomas, and although these lymphomas contained mutations in Cdk4, Fat3, and Lam3 (Fig. S1 G and Table S1), similar to human MCL patients, they did not harbor mutations in Atm or Trp53. Finally, we used the WES data to investigate the somatic hypermutation status in these Cond2-driven B cell lymphomas. Ighv mutations were analyzed in DNA from four $\mathrm{Ccnd2}^{\mathrm{Vav}}$ lymphomas compared with DNA from splenocytes from a Cre-negative littermate control. Two Cond2 ${ }^{\text {Vav }}$ lymphomas completely lacked Ighv mutations (Fig. $1 \mathrm{H}$ ), indicating that these murine unmutated MCL-like lymphomas originated from the mantle zone of secondary lymphoid organs, similar to the conventional human MCL subtype. In conclusion, we demonstrated that cyclin D2 overexpression in mice drives spontaneous B cell lymphoma formation, sharing features with human MCL patients.

\section{Cyclin D2 synergizes with p53 loss in B cells to form aggressive MCL-like lymphomas in mice}

The bicistronic transgene transcript encodes both cyclin D2 and the firefly luciferase reporter, which enabled us to trace neoplastic cells upon transplantation in secondary hosts using bioluminescence. Although $\mathrm{C}_{\mathrm{C} n d 2^{\mathrm{Vav}}}$ lymphomas engraft upon transplantation in immunodeficient nonobese diabetic/severe compromised immunodeficiency $\gamma$ (NSG) mice, they fail to develop full-blown aggressive MCL-like lymphoma within $3 \mathrm{mo}$ after transplantation (Fig. S2). This is in line with the absence of Atm or Trp53 mutations in these lymphomas. To increase the penetrance and decrease the latency of lymphoma formation, we investigated whether cyclin D2 overexpression would cooperate with other genetic alterations that frequently co-occur in MCL patients, such as mutations in the tumor suppressor gene TP53 (Beà et al., 2013; Greiner et al., 1996; Hernandez et al., 1996; Nadeu et al., 2020). To model this, we crossed conditional R26mediated Ccnd2 overexpression mice (R26-C Cnd2tg/tg) with conditional p53-knockout animals $\left(p 53^{f / f l}\right)$ in the B cell lineage 
A

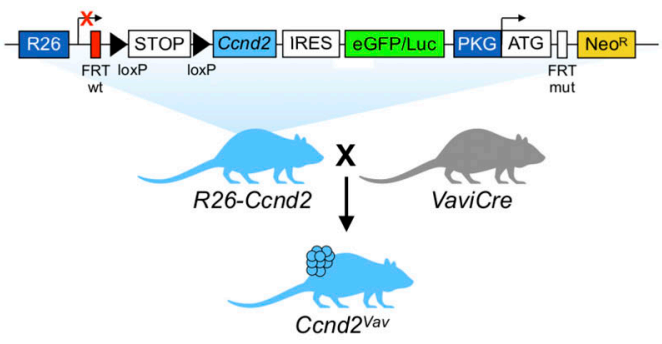

D
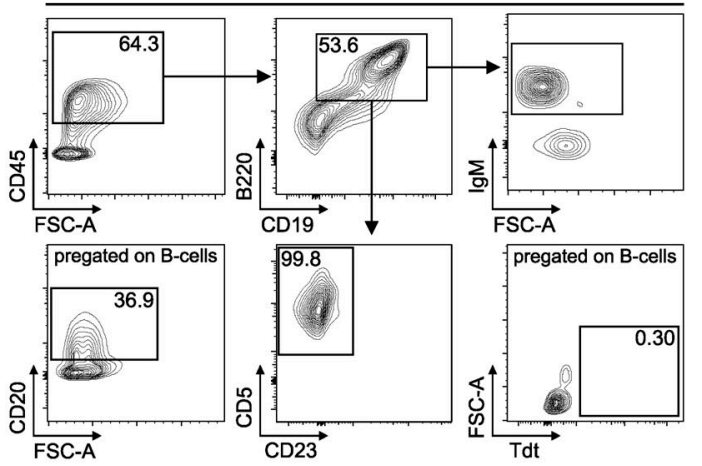

B

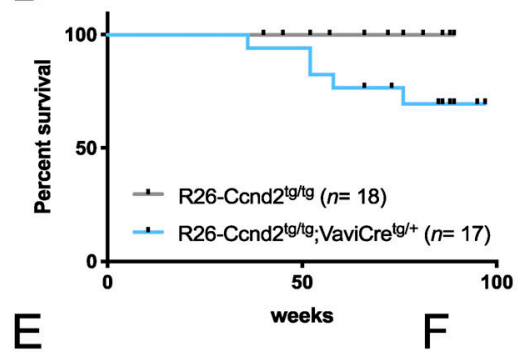

C
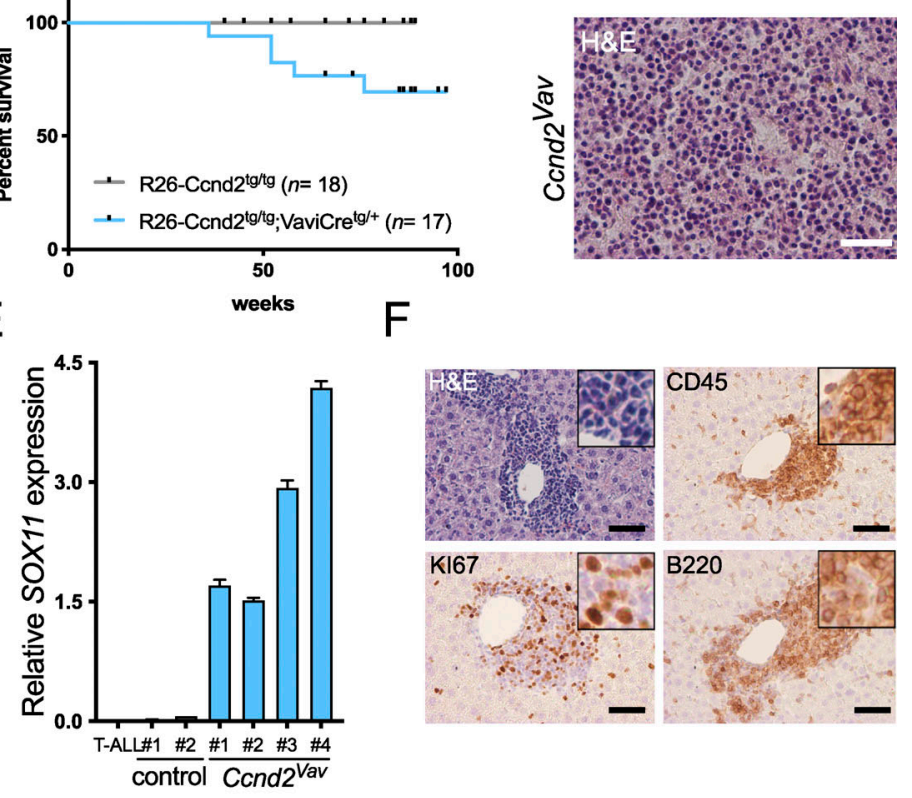

G
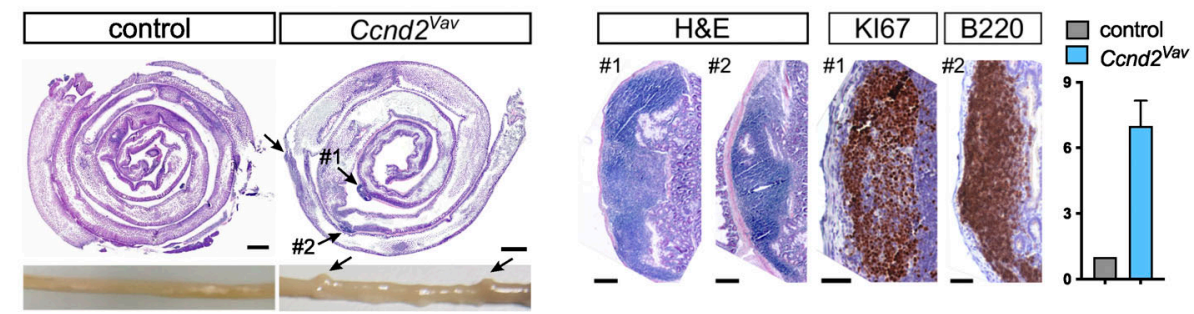

Figure 1. MCL-like lymphomas in a mouse model with hematopoietic cyclin D2 expression. (A) Schematic representation of R26-Ccnd2 mice that allow Cre-dependent conditional expression of a bicistronic transgene transcript, encoding for cyclin D2 and the EGFP/Luciferase reporter, from the R26 promoter. FRT, flippase recognition target; R26: ROSA26; IRES: independent ribosomal entry site; PKG, phosphoglycerate kinase 1; Neo ${ }^{\mathrm{R}}$, neomycin resistance gene; Luc, luciferase. (B) Kaplan-Meier survival curve of Cre-negative control (R26-Ccnd2tg/tg) versus R26-Ccnd2tg/tg; $V a v-i C r e^{\text {tg/+ }}$ (Ccnd2 $2^{v a v}$ ) mice. (C and D) H\&E-stained paraffin sections (C) and flow cytometric analysis (D) of a lymphoma from a 52-wk-old Ccnd2 ${ }^{\text {vav }}$ mouse. Scale bar, $50 \mu \mathrm{m}$. Single live cells were analyzed for the pan-hematopoietic CD45 markers; B cell markers B220 and CD19; and CD20, CD5, CD23, IgM, and Tdt. FSC-A, forward scatter area. (E) Quantitative PCR analysis for expression of Sox11 for healthy nonrecombined controls and Ccnd2 $2^{\text {vav }}$ lymphomas. As an extra Sox11-negative tumor control, RNA of a murine T cell lymphoblastic leukemia (T-ALL) sample was included. Error bars represent the SD of two technical replicates. (F and G) H\&E staining and immunohistochemistry for CD45, B220, and proliferation marker KI67 on paraffin sections of infiltrates or nodules in liver (F) and small intestine (G) in 36-wk-old (F) and 76wk-old (G) Ccnd2vav mice. Insets in F, magnified image. Scale bars in F, $50 \mu \mathrm{m}$. (G) Macroscopic view (bottom) and H\&E-stained transverse paraffin sections of Swiss rolls (top) of the small intestine. Scale bar, $500 \mu \mathrm{m}$. Right: H\&E-stained nodules (scale bar, $200 \mu \mathrm{m}$ ) and immunohistochemistry (scale bar, $50 \mu \mathrm{m}$ ) and a graph depicting the number of nodules $>200 \mu \mathrm{m}$ within the entire small intestine of control or Ccnd2 ${ }^{v a v}$ mice. Error bars represent the SD of two independent swiss rolls. (H) Graph depicting the number of single-nucleotide variants (SNVs) or insertions/deletions (indels) in Ighv genes of Ccnd2vav lymphomas.

(Fig. 2 A) using Mb1-Cre mice (Hobeika et al., 2006), which express the Cre-recombinase at the pro-B cell stage. Loss of p53 by itself triggered B cell malignancies within $400 \mathrm{~d}$ in $58 \%$ (11 of 19) of $p 53^{l l / f l ;} ; \mathrm{Mbl}-\mathrm{Cr} e^{\mathrm{tg} /+}$ (hereafter referred to as $\mathrm{p} 53^{\mathrm{Mbl}}$ ) mice with a median survival of $379 \mathrm{~d}$ (Fig. 2 B, dark blue curve). In combination with cyclin D2 overexpression, the R26-Ccnd2 $2^{\text {tg/tg}} ; \mathrm{p}^{2} \mathrm{f}^{\mathrm{l} / \mathrm{fl} \text {; }}$ $\mathrm{Mbl}-\mathrm{Cre} \mathrm{tg}^{\mathrm{tg}+}$ mice (hereafter referred to as $\mathrm{C} c \mathrm{nd2} / \mathrm{p} 53^{\mathrm{Mbl}}$ ) develop lymphadenopathies significantly sooner with a median survival of $268 \mathrm{~d}$ (Fig. 2 B, light blue curve). Lymphomas were frequently observed in peripheral lymphoid tissue, such as mandibular, axillary, inguinal, and mediastinal lymph nodes, and disseminated throughout the body, with infiltrations in the spleen, liver, peripheral blood (PB), and small intestine (Fig. S3). Consistent with an MCL pathophysiology, $C_{c n d 2} / p 53^{M b 1}$ mice displayed more frequent infiltration of proliferating tumor cells in the small intestine than $p 53^{\mathrm{Mb1}}$ mice (Fig. $2 \mathrm{C}$ ). Detailed flow cytometric analysis demonstrated that none of the analyzed $p 53^{\mathrm{Mbl}}$ lymphomas had an MCL-like immunophenotype. In contrast, 9 of $17 \mathrm{Ccnd2} / \mathrm{p} 53^{\mathrm{Mbl}}$ lymphomas showed a $\mathrm{CD} 19^{+} \mathrm{CD} 2 \mathrm{O}^{+} \mathrm{CD} 5^{+} \mathrm{CD} 23^{-}$ immunophenotype, similar to that of MCL patients and $\mathrm{CCnd2}_{2} \mathrm{Vav}^{\mathrm{Vav}}$ lymphomas (Fig. 2, D and E). Moreover, MCL-like Ccnd2/p53 $3^{\mathrm{Mbl}}$ lymphomas were $\operatorname{IgM}^{+} \operatorname{IgD}$, in line with human conventional MCLs, which are considered the oncogenic counterpart of naive mature B cells (Fig. 2 D). To investigate if MCL-like and nonMCL immunophenotypes were mutually exclusive, we performed flow cytometric analysis on all available tumors for each $C_{c n d 2} / p 53^{\mathrm{Mbl}}$ mouse that had at least one MCL-like lymphoma. We found that about half of the mice exhibited only MCL-like 
A
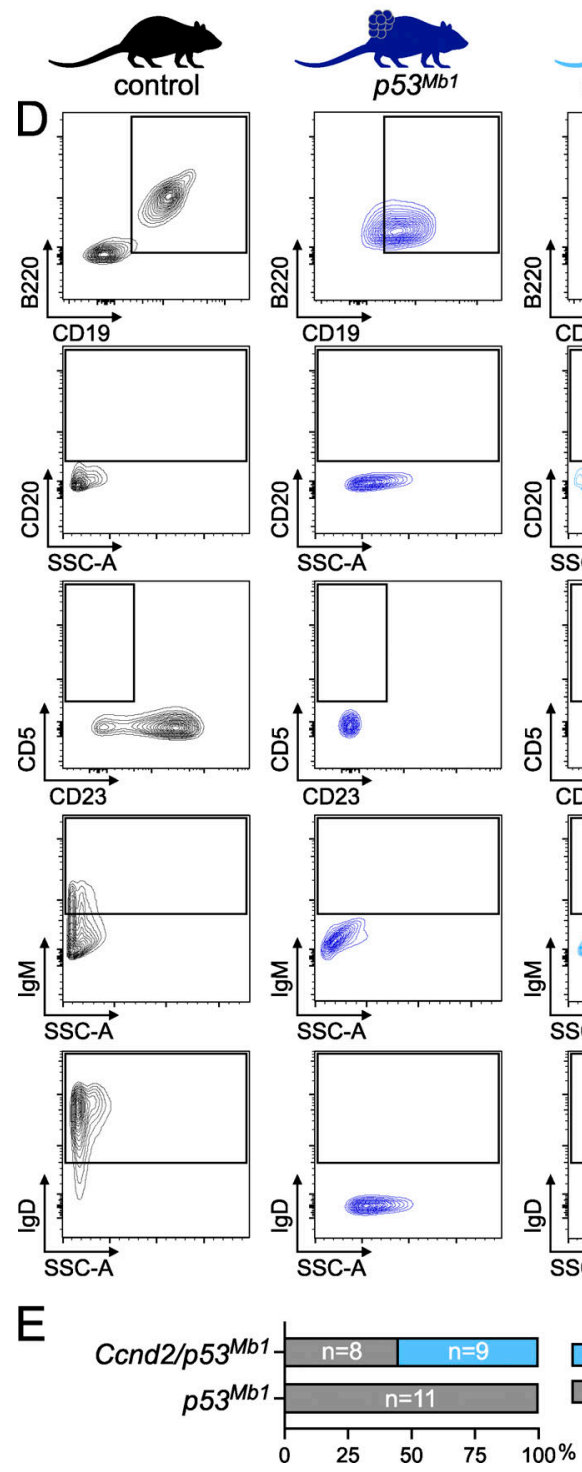

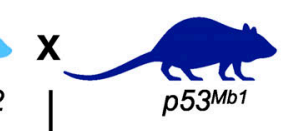

p53mb1
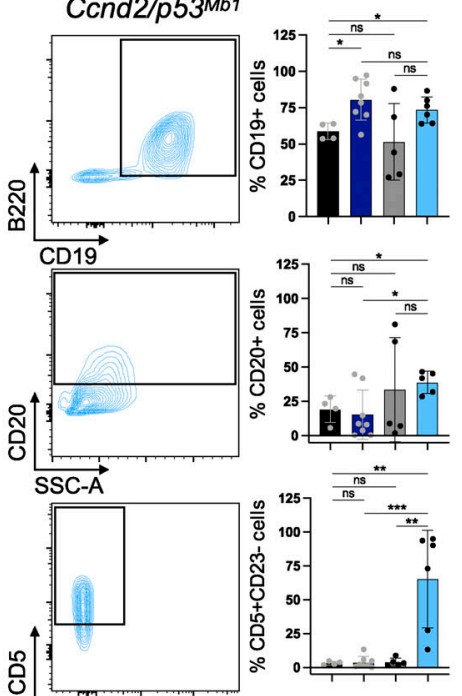

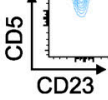
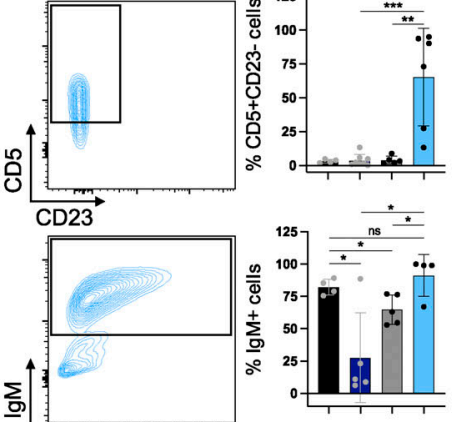

$\stackrel{\overrightarrow{S S C}-\mathrm{A}}{\mathrm{A}}$
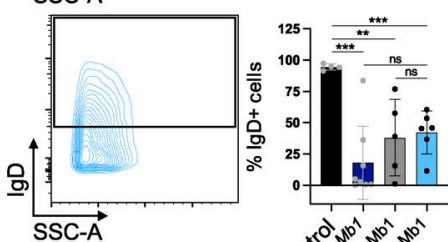

$\mathrm{MCL}$

non-MCL

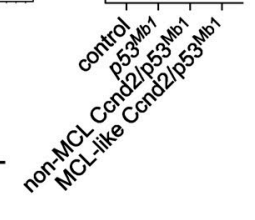

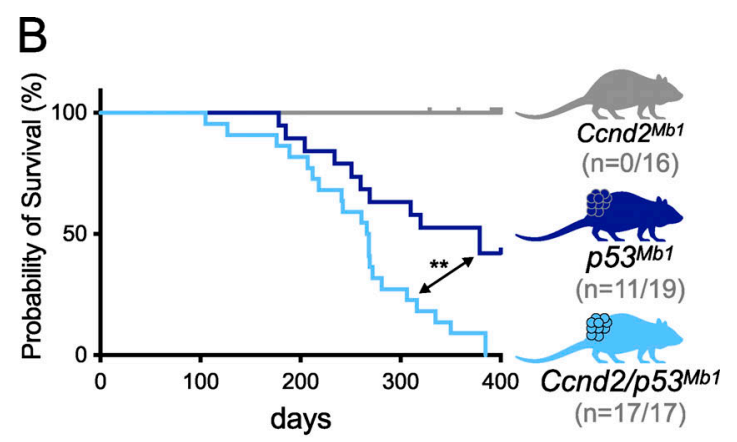

C
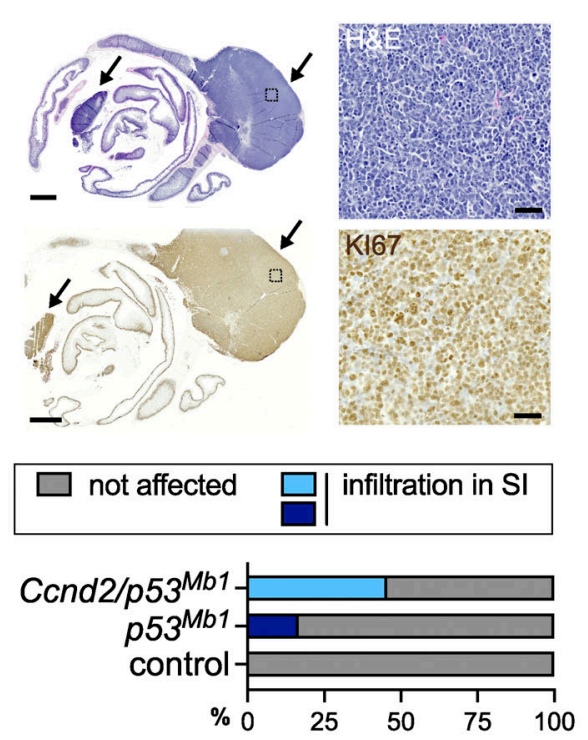

F

Ccnd2/p53mb1

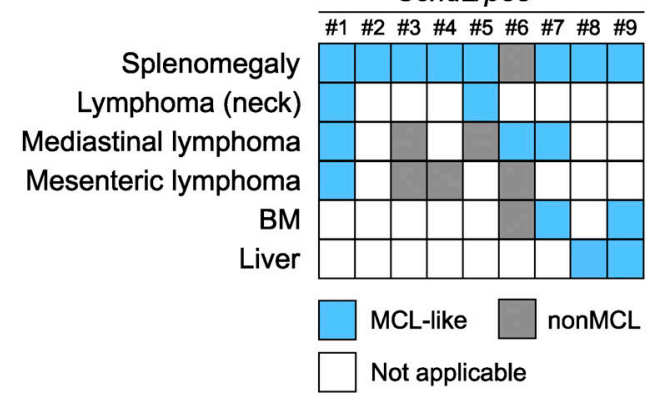

Figure 2. Cyclin D2 overexpression cooperates with loss of p53 in B cells to form MCL-like lymphomas. (A) Breeding scheme to obtain R26-Ccnd2tg/tg; $p 53^{f l / f l} ; M b 1-C r e^{t g /+}\left(C c n d 2 / p 53^{M b 1}\right)$ mice. (B) Kaplan-Meier survival curve of $C c n d 2^{M b 1}$, $p 53^{M b 1}$, and $C c n d 2 / p 53^{M b 1}$ mice. A log-rank (Mantel-Cox) test was used to compare curves from $p 53^{\mathrm{Mb1} 1}$ and $C \mathrm{Cnd} 2 / \mathrm{p} 53^{\mathrm{Mb1}}$ mice and showed a significant difference $\left({ }^{* *}, \mathrm{P}=0.0019\right)$. (C) H\&E staining (top) and KI67 immunohistochemistry (bottom) of transverse paraffin sections of Swiss rolls of the small intestine (SI) of a Ccnd2/p53Mb1 mouse. Scale bar, $500 \mu \mathrm{m}$. Tumor nodules are indicated with arrows, and magnifications are shown at right. Scale bar (magnification), $50 \mu \mathrm{m}$. Bottom: Graph depicts the percentage of mice that display tumor infiltration in the small intestine. (D) Flow cytometric analysis of $p 53^{\mathrm{Mb1}}(n=8)$ and $\mathrm{MCL}$-like $(n=6)$ and non-MCL $(n=5) \mathrm{Ccnd2} / \mathrm{p5} 3^{\mathrm{Mb1}}$ tumors and of four Cre-negative littermate controls. Single live CD45+ cells were analyzed for B cell markers B220 and CD19 and for CD5, CD23, IgM, and IgD. SSC-A, side scatter area. Representative flow plots are shown (left), and the frequencies of different populations were plotted in graphs (right). CD19+ cells were pregated on CD45 cells, and all other populations were pregated on $\mathrm{CD} 19^{+}$cells. Each dot represents a lymphoma from a different mouse. Error bars represent the SD of independent lymphomas. ${ }^{*}, \mathrm{P}<0.05 ;{ }^{* *}, \mathrm{P}<0.01{ }^{* * *}, \mathrm{P}<0.001$. (E) Graph depicts the percentage of $\mathrm{p} 53^{\mathrm{Mb} 1}$ or $\mathrm{Ccnd2} / \mathrm{p} 53^{\mathrm{Mb} 1}$ mice that exhibited an MCL-like immunophenotype. (F) Heatmap summarizing flow data of lymphomas from nine MCL-like Ccnd2/p53 ${ }^{M b 1}$ mice. Lymphomas were classified as MCL-like $\left(\mathrm{CD} 19^{+} \mathrm{CD} 2 \mathrm{O}^{+} \mathrm{CD}^{+} \mathrm{CD}^{-} 3^{-}\right)$or non-MCL $\left(\mathrm{CD} 19^{+} \mathrm{CD}^{-} \mathrm{O}^{-} \mathrm{CD}^{-}\right)$. 


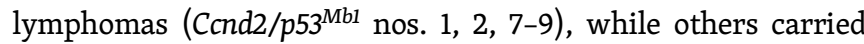
both MCL-like and non-MCL lymphomas (Fig. 2 F). Based on these observations, we conclude that $\mathrm{C}$ cnd2 overexpression increased the penetrance (58\% to $100 \%$ ) and decreased the latency ( 379 to $268 \mathrm{~d}$ ) of spontaneous B cell malignancies in a p53-null background and displayed a significant shift toward an MCL-like immunophenotype ( $0 \%$ to $53 \%$ ). Of note, within the time frame of this experiment $(400 \mathrm{~d})$, we did not observe any spontaneous lymphadenopathies in the $C \mathrm{cnd} 2^{\mathrm{Mbl}}$ cohort (Fig. $2 \mathrm{~B}$, gray curve).

A prerequisite for building preclinical models for MCL is the ability to recapitulate the disease in a short period of time. Therefore, we transplanted both non-MCL and MCL-like lymphomas in immunocompromised NSG mice (Fig. $3 \mathrm{~A}$ ) and found that these primary transplants developed into aggressive lymphomas within 5-7 wk or 5-6 wk, respectively (Fig. 3 B). Upon retransplantation of primary transplants in NSG mice, secondary C cnd2/p53 ${ }^{\mathrm{Mbl} 1}$ transplants were formed within 2-3 wk (Fig. 3 B). Flow cytometric analysis revealed that both primary and secondary transplants retained the immunophenotype of the primary tumor (Fig. 3, C and D). In conclusion, Ccnd2 overexpression synergizes with $\mathrm{p} 53$ loss in the malignant transformation of $\mathrm{B}$ cells to form aggressive and transplantable MCL-like tumors in mice.

\section{Murine cyclin D2-driven MCL-like tumors resemble B1a B cells}

To gain molecular insight into this murine MCL-like model, we performed transcriptional analysis on $\mathrm{Ccnd2} / \mathrm{p} 53^{\mathrm{Mb1}}$ lymphomas with or without the MCL immunophenotype. RNA-sequencing (RNA-seq) was performed on 5 non-MCL Ccnd2/p53 ${ }^{M b 1}$ lymphomas and 11 MCL-like Ccnd2/p53 ${ }^{M b 1}$ lymphomas. Samples clustered in a principal component analysis according to their phenotypic group (Fig. 4 A). We identified 3,850 differentially expressed genes (1,669 up and 2,181 down; $\left.\mathrm{P}_{\mathrm{adj}}<0.1\right)$ in MCL-like versus non-MCL lymphomas (Table S2). We performed enrichment analysis using the MCL-like versus non-MCL Ccnd2/ p53 ${ }^{M b 1}$ lymphoma signature and identified several MCL cell lines from the Cancer Cell Line Encyclopedia as top hits (Fig. 4 B). The top hit of this analysis was JVM-2, an MCL cell line with a $t(11 ; 14)$ translocation and high expression levels of cyclin D2 (Palmero et al., 1993; Winkler et al., 2005). Other hits were cell lines derived either from conventional MCL and chronic lymphocytic leukemia (CLL) patients, including EHEB and MEC-2, which also have high levels of both CD5 and cyclin D2 (Winkler et al., 2005). Of note, cell lines derived from multiple myeloma and diffuse large B cell lymphoma, two malignancies that also feature overexpression of cyclin D2 (Bergsagel et al., 2005; Hans et al., 2005; Hurt et al., 2004; Zlamalikova et al., 2016), did not show high transcriptional similarity to MCL-like Ccnd2/p53 ${ }^{M b 1}$ lymphomas. This demonstrates that our cyclin D2-driven murine MCL-like lymphomas are, at least to some extent, transcriptionally reminiscent of human MCL.

Notably, the most enriched phenotype in the MCL versus non-MCL C cnd2/p53 ${ }^{M b 1}$ lymphoma signature was increased B1 production (Fig. $4 \mathrm{C}$; $\mathrm{P}_{\mathrm{adj}}=0.0005$ ). In line with this, Ccnd2/ p53 ${ }^{M b 1}$ MCL-like lymphomas specifically expressed genes that were previously shown to be exclusively up-regulated in B1 cells (Mabbott and Gray, 2014). More specifically, 45\% (54 of 113) of B1-high genes from that study were present in our signature, and $59 \%$ of them were specifically up-regulated in MCL-like
Ccnd2/p53 ${ }^{M b 1}$ tumors (Fig. 4, D and E). Similarly, a positive correlation was observed by gene set enrichment analysis between the MCL-like versus non-MCL signature and transcripts that were differentially expressed between B1 and B2 cells (Fig. 4 F; Graf et al., 2019). B1 cells can be further subdivided into $\mathrm{CD}^{+} \mathrm{Bla}$ and $\mathrm{CD}^{-} \mathrm{B} 1 \mathrm{~b}$ subsets. Given that Cond2/p53 ${ }^{\mathrm{Mbl}}$ MCL-like lymphoma cells and Bla B cells displayed a similar $\mathrm{CD} 19^{+} \mathrm{CD} 5^{+} \mathrm{CD} 23^{-} \mathrm{IgM}^{+}$immunophenotype, we hypothesized that Bla cells could represent the cell of origin of these murine C cnd2-driven MCL-like lymphomas. In line with this, we confirmed specific characteristics of B1 cells, including low B220 expression and high levels of CD11b, pSTAT3, and IL-10, in MCL-like Cond2/p53 $3^{\mathrm{Mbl}}$ lymphomas (Fig. 3, G and H). In addition, and in line with its involvement in murine B1 cell development (Zhou et al., 2015), we also identified high levels of Arid3a in cyclin D2-driven MCL-like lymphomas (Fig. 4 H). Finally, Bla cells play a role in innate immunity and produce natural IgM antibodies as a first line of defense against bacteria and viruses (Dorshkind and Montecino-Rodriguez, 2007; Ehrenstein and Notley, 2010). Notably, we confirmed that cyclin D2-driven MCL-like lymphomas secrete high levels of IgM antibodies as compared with control tumors, both when these lymphomas were cultured ex vivo (Fig. 4 I) and when they were transplanted i.v. into immunocompromised NSG mice (Fig. $4 \mathrm{~J}$ ). Altogether, we provide transcriptional, immunophenotypic, and functional evidence that Bla B cells may serve as the cell of origin of our murine cyclin D2-driven MCLlike lymphomas.

\section{Cyclin D2 does not affect B cell development or B1a expansion in vivo}

Next, we wondered if cyclin D2 overexpression could skew B cell development or enhance expansion of Bla cells before tumor onset. First, we analyzed the expression of Ccnd2 in different B cell subsets. In line with previous findings (Solvason et al., 2000), Ccnd2 was the only D-type cyclin-encoding family member to be expressed in Bla and B1b cells from the peritoneal cavity (PerC; Fig. 5 A). Of note, compared with B2 and B1b cells, Bla cells had the highest levels of $C$ cnd2 in both the spleen and PerC (Fig. 5 B), and Ccnd2 expression was even further increased in Bla and Blb PerC cells from healthy 10-20-wk-old Ccnd2/ $p 53^{M b 1}$ mice compared with $p 53^{M b 1}$ mice (Fig. 5 C). Next, we analyzed B2 progenitor populations in bone marrow (BM) and B1a cells in $\mathrm{PB}$ and spleens of young and old (>6 mo) Cre-negative controls and tumor-free $C_{c n d 2} 2^{M b 1}, p 53^{M b 1}$, and $C_{c n d} 2 / p 53^{M b 1}$ mice using flow cytometry. We found that cyclin D2 overexpression did not have any major effect on B2 cell development in the BM (Fig. $5 \mathrm{D}$ ) or on the expansion of Bla cells in the PB, BM, PerC, or spleen (Fig. 5, E-G). These data suggest that oncogenic transformation of Bla cells is most likely a late-stage event that is facilitated by cyclin D2 overexpression and loss of p53.

\section{Ccnd2/p53 ${ }^{M b 1}$ lymphomas have B1-specific BCR and elevated BCR signaling}

In contrast to conventional B2 cells, B1 cells are long-lived and can self-renew due to continuous self-antigen-driven BCR activation, rendering them highly susceptible to oncogenic transformation. B1 cells have a receptor repertoire that is biased toward bacterial antigens and self-antigens, such as phosphatidylcholine (PtC), a 
A

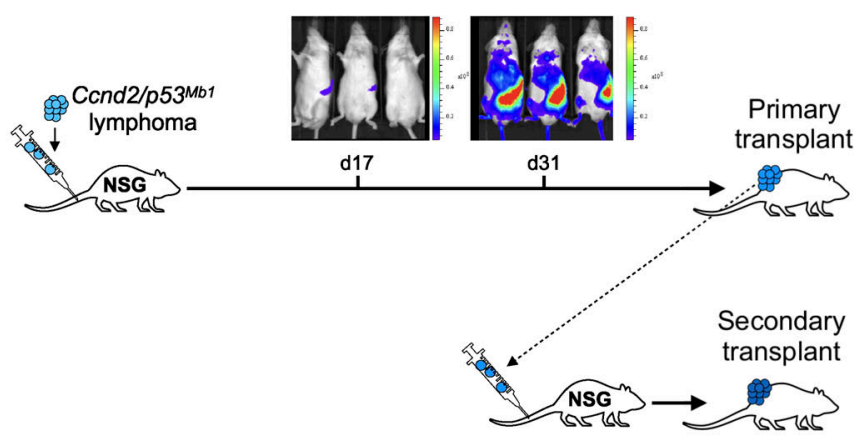

C

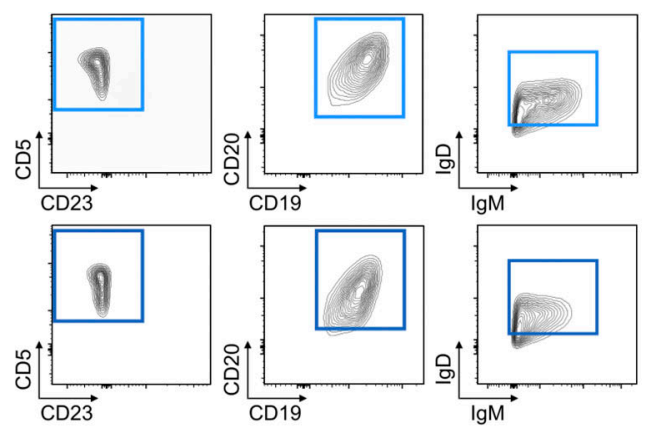

B

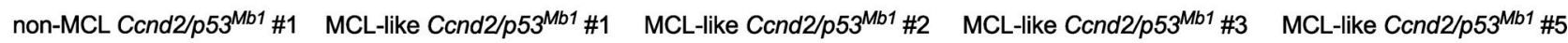
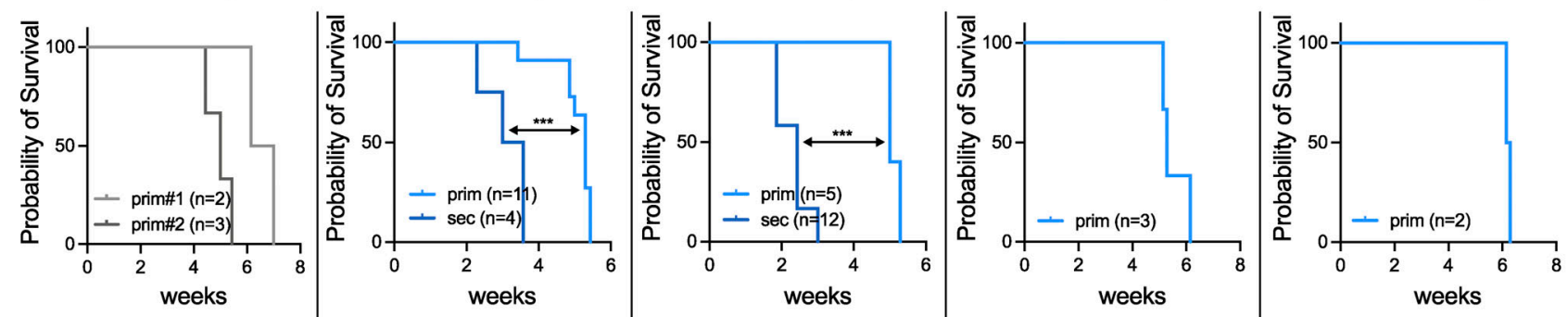

D
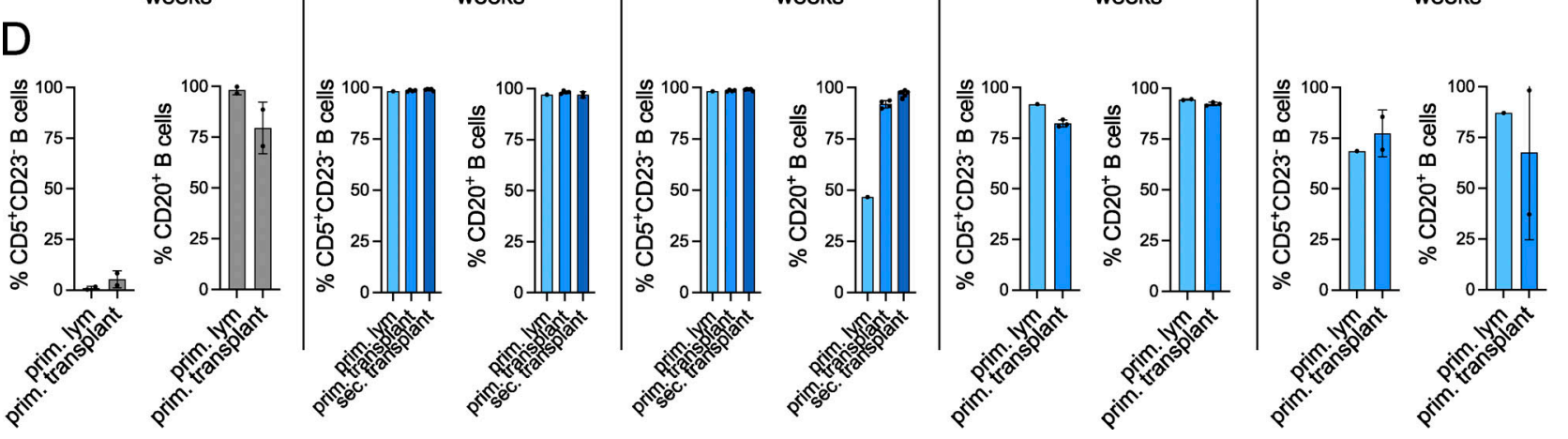

Figure 3. Cyclin D2-driven lymphomas are transplantable. (A) Scheme of serial transplantation of Ccnd2/p53 ${ }^{\text {Mb1 }}$ lymphomas in immunocompromised NSG mice using tail vein injections. Bioluminescence measurements are shown at days 17 and 31 for primary transplants of Ccnd2/p53 ${ }^{M b 1}$ lymphoma 1 (top). Primary transplants were reinjected into NSG mice to obtain secondary transplants. (B) Kaplan-Meier survival curves of primary (prim) and secondary (sec) Ccnd2/ $p 53^{\mathrm{Mb} 1}$ transplants. For each transplant, the number of NSG mice $(n)$ is indicated on the graph. A log-rank (Mantel-Cox) test was used to compare curves from primary and secondary $C \mathrm{cnd} 2 / \mathrm{p} 53^{\mathrm{Mb1}}$ transplants and showed a significant difference $\left(* * *, \mathrm{P}=0.0005[\mathrm{MCL}-\right.$ like $\# 1] ;{ }^{* * *}, \mathrm{P}=0.0003[\mathrm{MCL}-\mathrm{like} \# 2]$ ). (C) Representative flow cytometric analysis of primary and secondary C cnd2/p53 $3^{\mathrm{Mb} 1}$ transplants. (D) Frequencies of $\mathrm{CD} 5^{+} \mathrm{CD} 23^{-}$(left) or CD20 $\mathrm{C}^{+}$(right) B cells (pregated on $\mathrm{CD}_{4} 5^{+} \mathrm{CD} 19^{+}$single live B cells) in primary and secondary $\mathrm{C}\left(\mathrm{nd} 2 / \mathrm{p} 53^{\mathrm{Mb} 1}\right.$ transplants. Each dot represents a different primary lymphoma or different transplants that were propagated in independent NSG mice. Error bars represent the SD of independent lymphomas.

phospholipid and major component of biological membranes. PtC is predominantly recognized by BCRs that use preferentially $\mathrm{V}_{\mathrm{H}} 11$ or $\mathrm{V}_{\mathrm{H}} 12$. Given the fact that $\mathrm{C} \mathrm{cnd} 2 / \mathrm{p} 53^{\mathrm{Mbl}}$ lymphomas most likely originate from Bla cells, we investigated the B1-specific BCR repertoires in $p 53^{\mathrm{Mbl}}$ and $\mathrm{C}_{\mathrm{C}} \mathrm{d} 2 / \mathrm{p} 53^{\mathrm{Mb1}}$ lymphomas by performing quantitative PCR analysis for $\mathrm{V}_{\mathrm{H}} 11$ or $\mathrm{V}_{\mathrm{H}} 12$. In line with previous results, only MCL-like Ccnd2/p53 ${ }^{M b 1}$ lymphomas expressed $\mathrm{V}_{\mathrm{H}} 11$ or $\mathrm{V}_{\mathrm{H}} 12$ (Fig. 6, A and $\mathrm{B})$. To test if these BCRs were indeed PtC reactive, we measured PtC liposome reactivity of $p 53^{\mathrm{Mbl}}$ and $\mathrm{C}_{\mathrm{A}} \mathrm{c} 2 \mathrm{2} / \mathrm{p} 53^{\mathrm{Mbl}}$ lymphomas by flow cytometry using fluorescent PtC liposomes. We found that only MCL-like C cnd2/p53 ${ }^{M b 1}$ lymphomas that expressed Bla-enriched VH segments exhibited PtC reactivity (Fig. $6 \mathrm{C}$ ). Similar results were found in transplants of non-MCL and MCL-like Ccnd2/p53 ${ }^{\mathrm{Mbl}} \mathrm{lym}$ phomas (Fig. S4). These data strengthen the idea that recurrent activation of self-reactive BCRs might aid the transformation of Ccnd2-overexpressing Bla B cells. To directly test this hypothesis, we analyzed BCR activity in these MCL-like lymphomas using transcriptional analysis and phospho-flow cytometry. Pathway enrichment analysis using the MCL-like versus non-MCL $C \mathrm{cnd} 2 / \mathrm{p} 53^{\mathrm{Mbl}}$ lymphoma signature identified the BCR signaling pathway as the top hit among all Kyoto Encyclopedia of Genes and Genomes 2019 human pathways (Fig. 6 D). In addition, we analyzed activation of Bruton's tyrosine kinase (BTK), a pivotal component of the BCR pathway, in these MCL-like lymphomas using phospho-flow cytometry. Higher phospho-BTK (Y223) levels were seen in primary MCL-like lymphomas that expressed Bla-specific VH segments, as compared with MCL-like lymphomas without Bla-specific BCRs or non-MCL control tumors, both under steady-state conditions and 
A

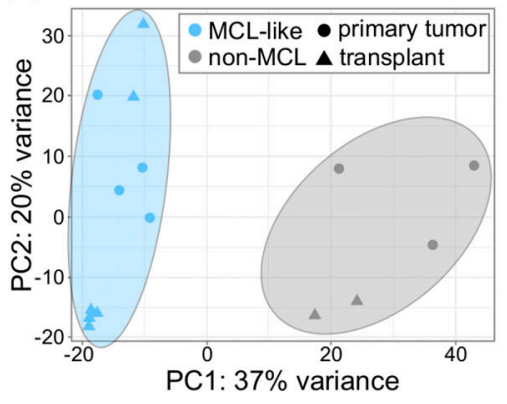

B

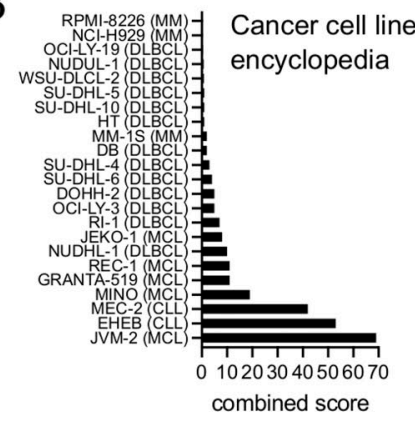

C

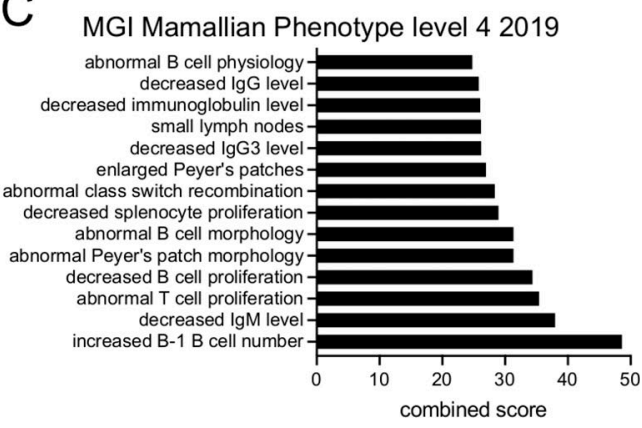

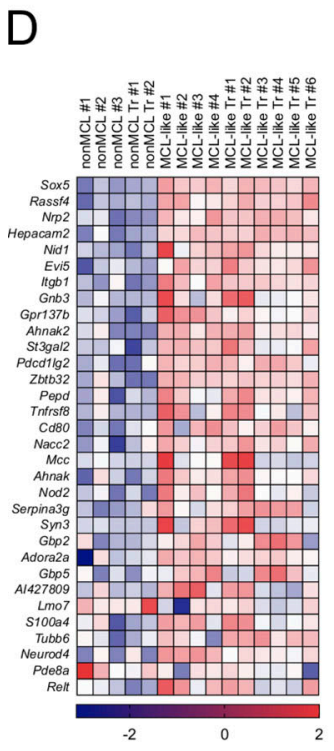

E

G

B1 vs all other B-cells

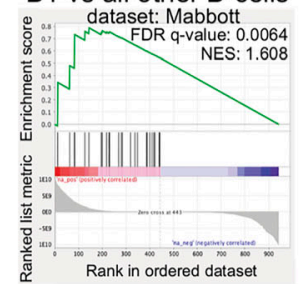

$\mathrm{F}$

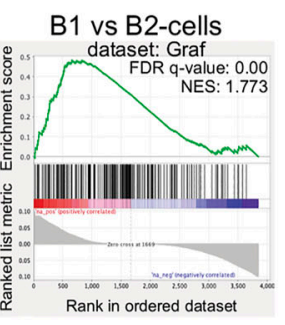

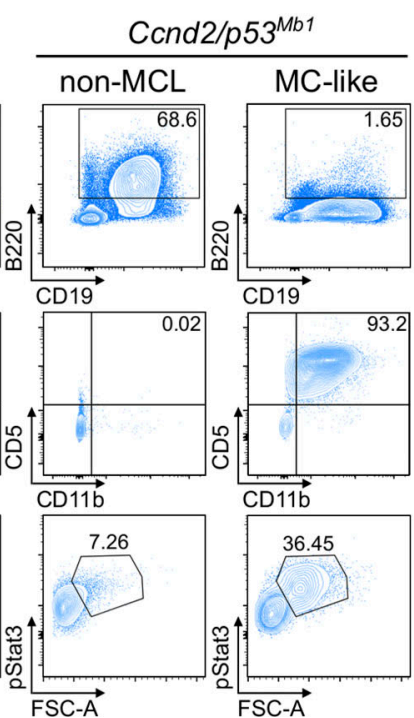
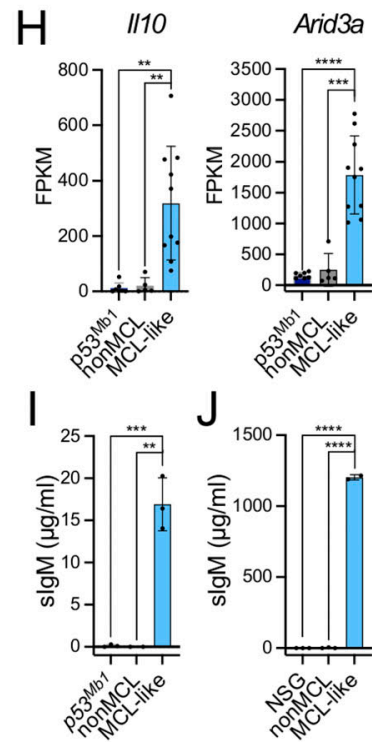

Figure 4. MCL-like cyclin D2-driven lymphomas are alike in B1a and B cells. (A) Principal component (PC) analysis for C $\mathrm{cnd} / \mathrm{p} 53^{\mathrm{Mb1}}$ lymphomas with or without an MCL-like immunophenotype. (B and C) Enrichment analysis for the $M C L$ versus non-MCL transcriptional signature and datasets from the Cancer Cell Line Encyclopedia (B) and Mouse Genome Informatics Mammalian Phenotype Level 42019 (C). DLBCL, diffuse large B cell lymphoma; MM, multiple myeloma. (D) Heatmap for B1-specific genes in primary and transplanted (Tr) non-MCL and MCL-like Ccnd2/p53 ${ }^{M b 1}$ lymphomas. (E and F) Gene set enrichment analysis for the MCL-like versus non-MCL transcriptional signature and gene sets that compare B1 cells with all other B cell subsets (E) or with B2 cells (F). FDR, false discovery rate; NES, normalized enrichment score. (G-J) Flow cytometric analysis for CD19, B220, CD5, CD11b, and phospho-STAT3 (pStat3; G); mRNA

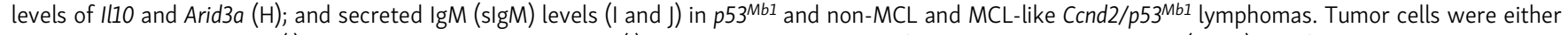
cultured ex vivo overnight (I) or transplanted into NSG mice (J). PB serum was collected from noninjected NSG mice $(n=3)$ and from NSG mice that were injected with MCL-like $(n=2)$ or non-MCL $(n=3) \mathrm{Ccnd2} / \mathrm{p} 53^{\mathrm{Mb1}}$ lymphomas. FPKM, fragments per kilobase of transcript per million mapped reads; FSC-A, forward scatter area. Error bars in $\mathrm{H}-\mathrm{J}$ represent the SD of independent lymphomas. $\mathrm{P}$ values in $\mathrm{H}:{ }^{* *}, \mathrm{P}=0.0014\left(\mathrm{Il10}, \mathrm{p5} 3^{\mathrm{Mb1}} \mathrm{vs}\right.$. MCL-like) and ${ }^{* *}, \mathrm{P}=0.0073$ (Il10, non-MCL vs. MCL-like); ${ }^{* * *}, \mathrm{P}<0.0001$ and ${ }^{* * *}, \mathrm{P}=0.0002$ (Arid3a). $\mathrm{P}$ values in I: ${ }^{* *}, \mathrm{P}=0.0055 ;{ }^{* *}, \mathrm{P}=0.0008 . \mathrm{P}$ values in $\mathrm{J:}{ }^{* * *}, \mathrm{P}<0.0001$.

upon IgM stimulation (Fig. 6, E and F). Strikingly, only MCL-like Ccnd2/p53 ${ }^{\mathrm{Mbl}}$ lymphomas that bear Bla-specific VH segments and feature elevated phospho-BTK levels were sensitive to the BTK inhibitor ibrutinib (Fig. $6 \mathrm{G}$ ), which has been successfully used to treat relapsed or refractory MCL patients (Wang et al., 2013). In conclusion, cyclin D2-driven murine MCL-like lymphomas often have Bla-specific self-reactive BCR repertoires and increased $\mathrm{BCR}$ activity; hence, continuous self-antigen-driven triggering of Bla cells may aid in their long-term self-renewal and makes them a prime target for oncogenic transformation.

\section{MCL-like cyclin D2-driven lymphomas exhibit MALT1 protease activity}

Finally, we searched for additional druggable signaling complexes within the pathways enriched in murine Bla-like MCL tumors and identified signaling pathways with Gene Ontology terms "BCR," "T-cell receptor (TCR)," and "NF- $k B$ signaling" as potential therapeutic targets (Fig. $6 \mathrm{D}$ ). Signals from both the BCR and TCR converge to the CARD11-BCL10-MALT1 (CBM) signalosome complex, which relays signals to the nucleus via the NF- $\kappa B$ pathway. Multiple well-known NF- $\kappa B$ genes were up-regulated in murine MCL-like lymphomas (Fig. $7 \mathrm{~A}$ ), and promoters of differentially expressed genes were enriched for RELA and NF-kB motifs (Fig. 7 B). Remarkably, all three components of the CBM signalosome complex were transcriptionally up-regulated in MCL-like $C_{c n d 2} / \mathrm{p}^{2} 3^{\mathrm{Mbl}}$ lymphomas (Fig. 7 A). Moreover MALT1, an essential component of the CBM complex, was previously proved to be essential for the generation and maintenance of B1 cells (Demeyer et al., 2016; Ruefli-Brasse et al., 2003; Ruland et al., 2003), and 
A

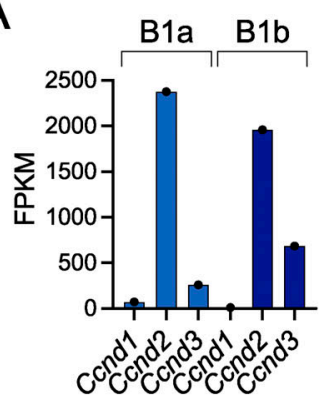

B

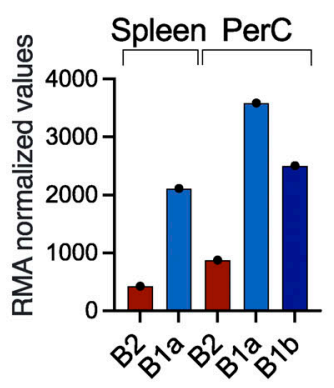

C

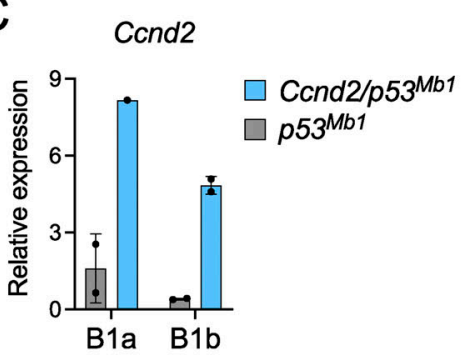

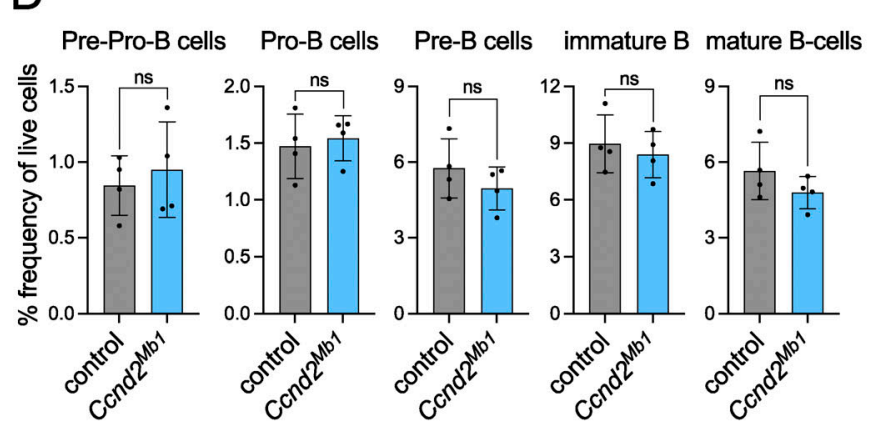

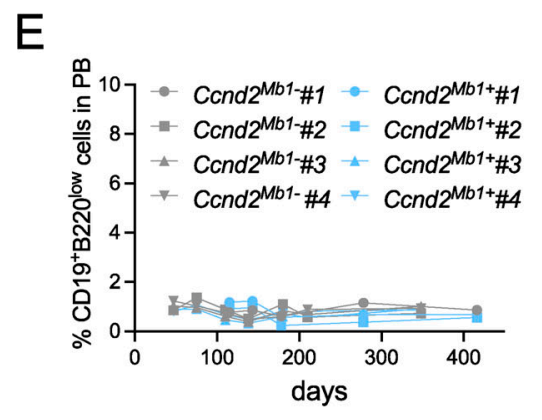

F $\quad B 1$ cells in PB

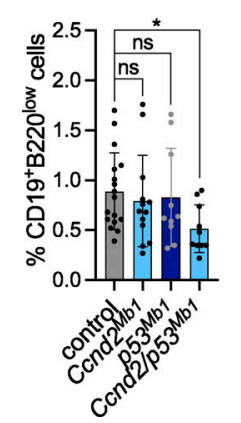

D
G
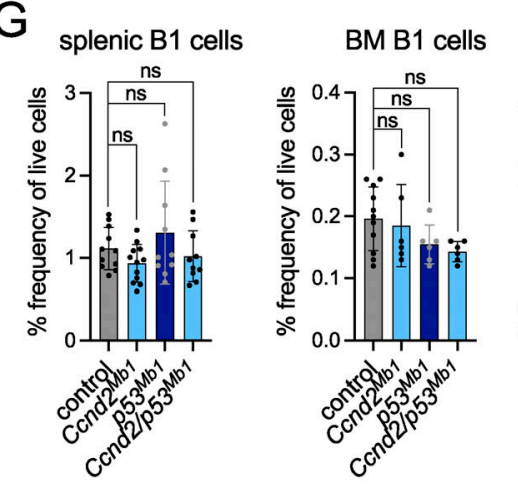

total splenic $\mathrm{B} 1$ cells
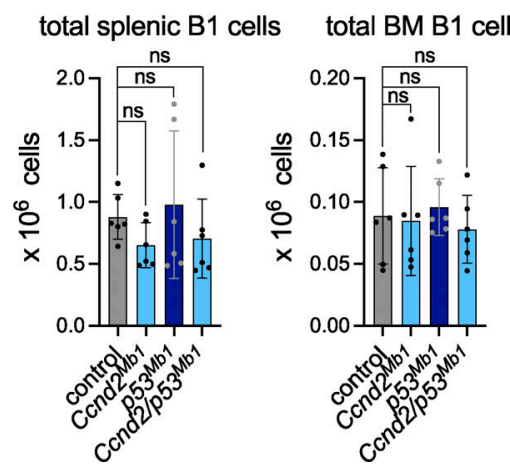

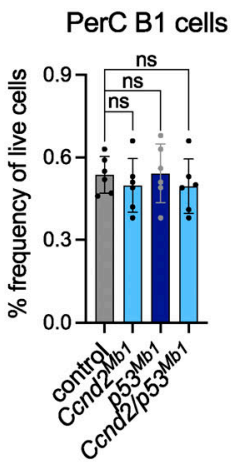

Figure 5. Cyclin D2 does not affect B2 cell development or B1 cell expansion. (A) Expression of Ccnd1, Ccnd2, and Ccnd3 in B1a and B1b cells from PerC. FPKM, fragments per kilobase of transcript per million mapped reads. (B) Expression of Ccnd2 in a sorted B cell subset from the spleen and PerC, including B2, B1a, and B1b cells. Follicular B cells were used as splenic B2 cells. Data in A and B were taken from https://www.immgen.org/. RMA, robust multiarray average. (C) Ccnd2 expression in

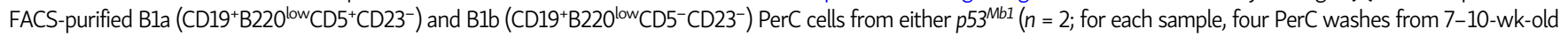
mice were pooled) or $\mathrm{C} n \mathrm{nd} 2 / \mathrm{p} 53^{\mathrm{Mb1}}$ ( $n=2$; for each sample, three PerC washes from 12-15-wk-old mice were pooled) mice. (D) B2 BM progenitor populations in 10-wk-old healthy $\mathrm{CCnd2}^{\mathrm{Mb1}}$ and Cre-negative littermate control mice. B cell populations were defined as follows: Pre-Pro-B (B220 $\left.{ }^{+} \mathrm{CD} 19^{-} \mathrm{CD} 43^{+} \mathrm{CD} 93^{+} \mid \mathrm{gM} \mathrm{M}^{-} \mathrm{CD} 24^{\mathrm{low}}\right)$, Pro-B

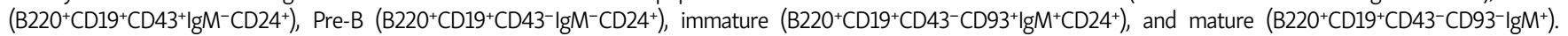
(E) CD19+B220 low B1 cell fractions (pregated on single live CD45 cells) in PB of control $(n=4)$ and $\mathrm{Ccnd}^{+\mathrm{Mb1}}(n=4)$ mice over time. (F) Flow cytometric analysis of B1 cell fractions in PB of $C c n d 2^{M b 1}(n=13), p 53^{M b 1}(n=10), C c n d 2 / p 53^{M b 1}(n=10)$, and Cre-negative littermate control $(n=17)$ mice. ${ }^{*}, P=0.0107$. (C) Frequency and total number of B1 cells in the spleen, BM, and PerC cells of $C \mathrm{Cnd} 22^{\mathrm{Mb1}}, \mathrm{p} 53^{\mathrm{Mb1}} \mathrm{Ccnd2} / \mathrm{p} 53^{\mathrm{Mb1}}$, and Cre-negative littermate control mice (at least six mice/group). Each dot represents a different mouse sample. Error bars represent SD.

increased MALT1 protease activity has been reported in a subset of MCL patients and cell lines (Dai et al., 2017). We examined MALT1 protease activity in our murine cyclin D2driven lymphomas via Western blot analysis for cleavage of known substrates, BCL10, cylindromatosis (CYLD), and N4BP1 (Rebeaud et al., 2008; Staal et al., 2011; Yamasoba et al., 2019). Three of four primary MCL-like Ccnd2/p53 $3^{\mathrm{Mbl}}$ lymphomas exhibited MALT1 protease activity (Fig. 7, C and D), while no cleavage of BCL10, CYLD, and N4BP1 was observed in nonMCL controls.

\section{Therapeutic targeting of MALT1 activity in Bla-like murine MCLs}

Because it was shown that MALT1 protease activity is required for the development and maintenance of Bla cells in mice (Bornancin et al., 2015; Demeyer et al., 2016; Gewies et al., 2014; Yu et al., 2015), MALT1 may act as a novel therapeutic target to treat Bla/MCL-like lymphoma. First, we tested a panel of MALT1 inhibitors (Fig. 8 A), including chlorpromazine (CPZ) and mepazine (MPZ; Jacobs et al., 2020; Nagel et al., 2012; Schlauderer et al., 2013), as well as MLT-748 and its structural 
A

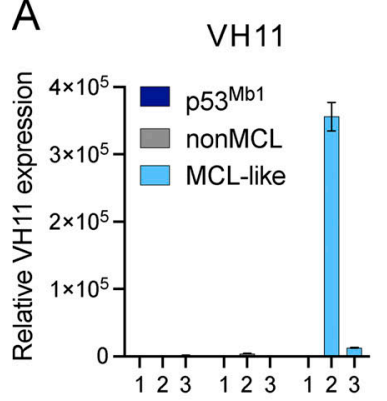

$\mathrm{E}$

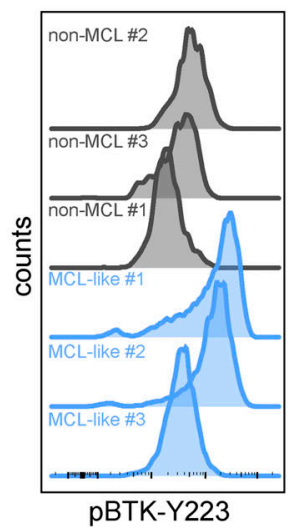

B

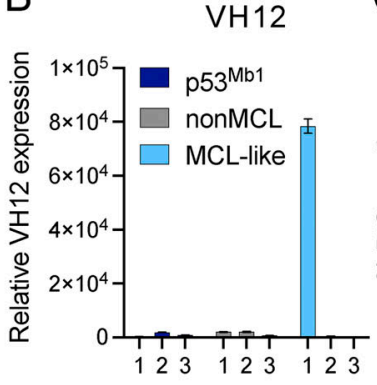

$\mathrm{F}$

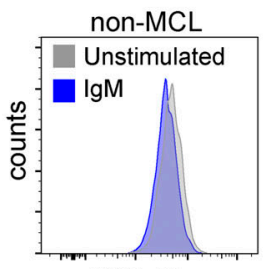

MCL-like

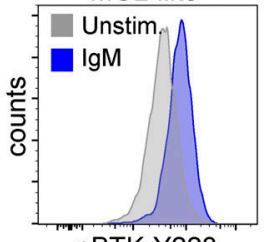

pBTK-Y223

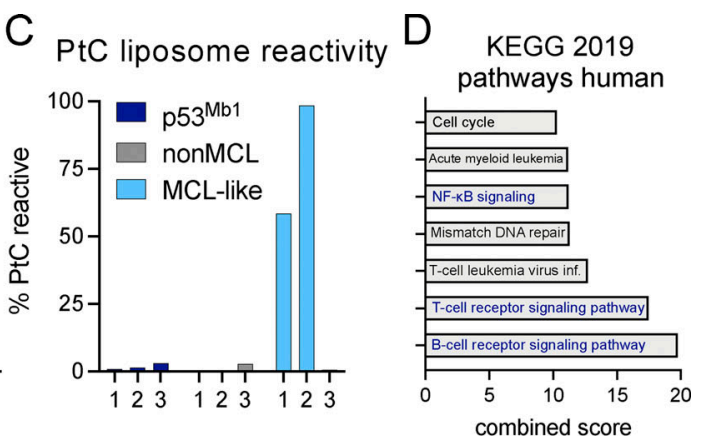

G

Figure 6. MCL-like cyclin D2-driven lymphomas have B1a-specific BCRs and increased BCR signaling. (A and B) qRT-PCR analysis for B1a-specific heavy chain variable domains $V_{H} 11(A)$ and $V_{H} 12(B)$ on $C D N A$ of $p 53^{M b 1}$ lymphomas and $C c n d 2 / p 53^{M b 1}$ lymphomas with or without an MCL-like immunophenotype. Error bars represent the SD of two technical replicates. (C) Frequency of PtC-liposome-reactive cells in lymphomas that were pregated on single live CD19+ cells. (D) Enrichment analysis for the MCL-like versus non-MCL transcriptional signature and the human Kyoto Encyclopedia of Genes and Genomes (KEGG)

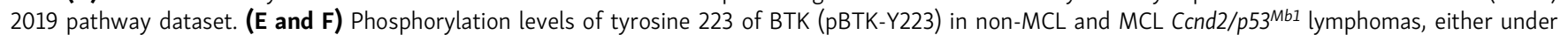
steady state (E) or upon 30-min stimulation with $10 \mu \mathrm{g} / \mathrm{ml} \operatorname{lgM}$ Fab fragments (F). (G) Dose-response curve for ibrutinib in non-MCL and MCL-like CCnd2/p53 ${ }^{M b 1}$ lymphomas.

analogue MALTli\#2 (Quancard et al., 2019), on both murine cyclin D2-driven lymphomas with or without MALT1 activity and on two human MCL cell lines, REC-1 and MINO, with reported high MALT1 activity (Dai et al., 2017). We found that Bla/ MCL-like C $c n d 2 / p 53^{M b 1}$ lymphomas with MALT1 activity were highly sensitive to treatment with MLT-748 and MALTli\#2 and to a lesser extent also to CPZ and MPZ (Fig. 8, B and C). No effects for MLT-748 and MALTli\#2 were seen on the ex vivo growth of non-MCL Ccnd2/p53 $3^{\text {Mbl }}$ lymphomas without MALT1 activity, demonstrating their selectivity. In contrast, mild effects at the highest tested concentrations were seen for the allosteric MALT1 inhibitors CPZ and MPZ, for which it is known they are less selective and also bind other targets (Ban, 2007; Miller, 2009a; Miller, 2009b). The differences in potency of inhibiting MALT1 were confirmed in PMA/ionomycin-stimulated Jurkat cells, where MALT1-induced cleavage of CYLD was blocked with $1 \mu \mathrm{M}$ MLT-748 or MALTli $\# 2$ but required $30 \mu \mathrm{M} \mathrm{CPZ} \mathrm{or} \mathrm{MPZ}$ (Fig. 8 D). Next, we selected CPZ and MALTlï\#2 and analyzed their ability to block MALT1-mediated substrate cleavage in murine MCL-like lymphoma. Therefore, we treated fresh splenic cells from an MCL-like Ccnd2/p53 ${ }^{\text {Mbl }}$ allograft (MCL-like \#2) for 12 and $24 \mathrm{~h}$ with increasing concentrations (as determined in Fig. 8 D) of either CPZ or MALTli\#2. We found that a 12-h treatment with $1 \mu \mathrm{M}$ MALTli\#2 is sufficient to block MALT1mediated cleavage of CYLD and N4BP1 (Fig. $8 \mathrm{E}$ ). In contrast, CYLD cleavage was only reduced after 12-h treatment with $50 \mu \mathrm{M} \mathrm{CPZ}$ (Fig. $8 \mathrm{E}$ ). In conclusion, we selected MALTli\#2 from a panel of four MALT1 inhibitors as one of the most potent agents that could block MALT1 protease activity and in selectively killing MCL-like lymphoma cells in vitro.

Next, we wanted to target B1 cells or Bla-derived lymphoma cells by pharmacological inhibition of MALT1 in vivo. First, we treated wild-type C57BL6 mice for 1 wk with $30 \mathrm{mg} / \mathrm{kg}$ MALTli\#2 (twice daily) and analyzed B1 cell fractions in the PerC. In line with the above-mentioned genetic studies (Bornancin et al., 2015; Demeyer et al., 2016; Gewies et al., 2014; Yu et al., 2015), B1 cells were highly sensitive to pharmacological inhibition of MALT1 protease activity with a fivefold reduction of peritoneal B1 cells (Fig. 9, A and B). A similar observation was made when wild-type mice were treated with $10 \mathrm{mg} / \mathrm{kg} \mathrm{CPZ}$ (Fig. S5, A and B). Second, we wondered whether Bla/MCL-like cyclin D2-driven lymphomas would also be sensitive to MALT1 protease inhibition in vivo. The firefly luciferase reporter allowed us to preclinically evaluate the effects of MALT1 inhibition by MALTli\#2 on the development of MCL in vivo. To this end, a primary MCL-like $C$ cnd2/p53 ${ }^{\mathrm{Mbl}}$ lymphoma with MALT1 

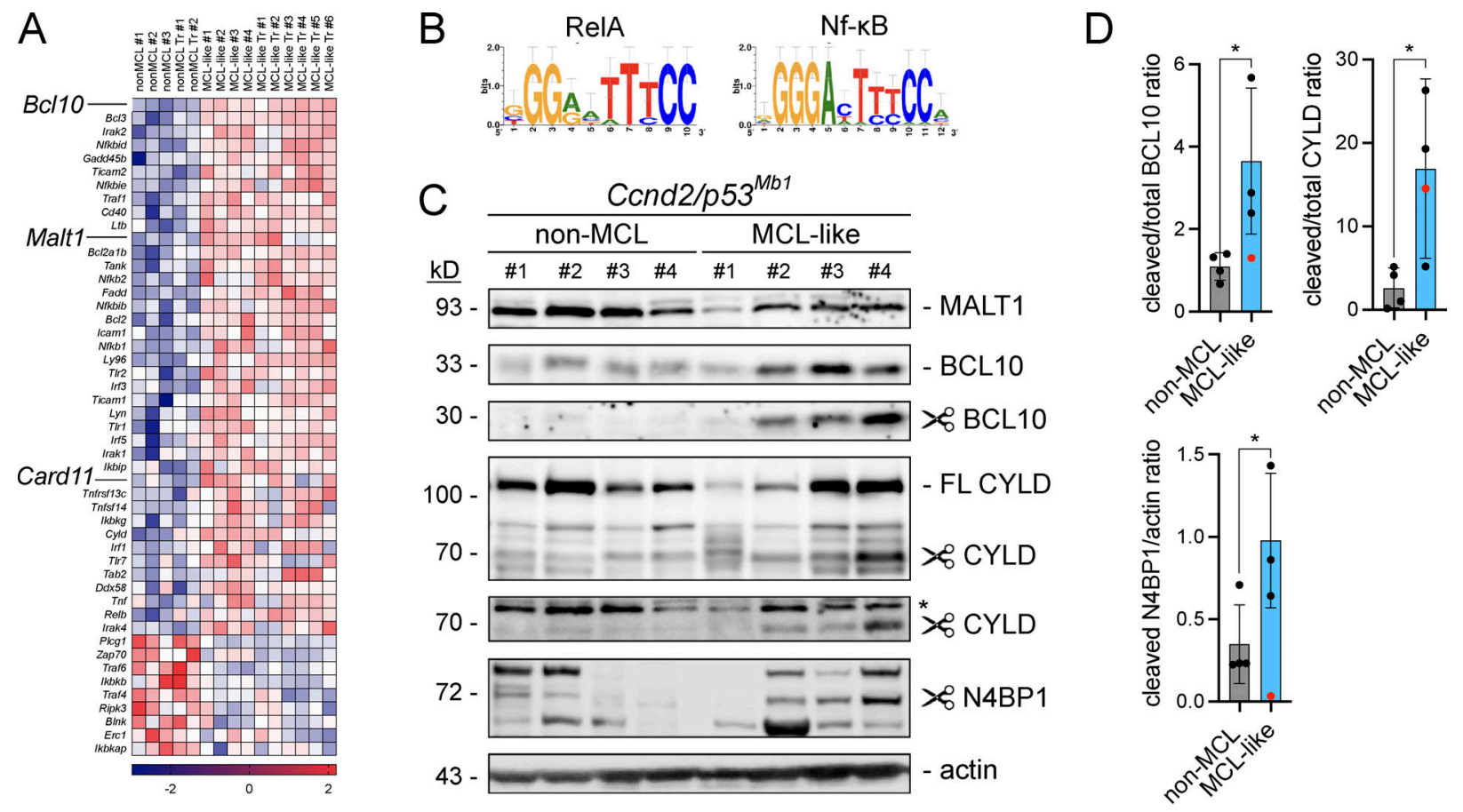

Figure 7. Cyclin D2-driven B1a/MCL-like lymphomas have increased MALT1 activity. (A and B) Heatmap for NF-KB pathway genes (A) and cis-regulatory enrichment analysis (B) in primary and transplanted ( $\mathrm{Tr}$ ) non-MCL and MCL-like $\mathrm{C} c \mathrm{nd} 2 / \mathrm{p} 53^{\mathrm{Mb} 1}$ lymphomas. (C) Western blot analysis of CBM complex members MALT1 and BCL10 and cleavage of MALT1 substrates BCL10, CYLD, and N4BP1 for non-MCL and MCL-like Ccnd2/p53Mb1 lymphomas. For BCL10 and CYLD, we used two different antibodies that recognize either the full-length or cleaved protein. Actin was used as a loading control. The asterisk denotes an aspecific band. (D) Levels of cleaved BCL10, CYLD, or N4BP1 were normalized against their respective full-length (FL) counterpart or actin. The red dot indicates the MCL-like lymphoma (\#1) that lacks endogenous MALT1 activity, and this value was excluded from the statistical analysis. Error bars represent SD. BCL10: $*, P=0.0333 ; C Y L D:{ }^{*}, P=0.0450 ; N 4 B P 1:{ }^{*}, P=0.0488$.

protease activity (MCL-like \#2) was transplanted in NSG mice (Fig. 9 C). Successful engraftment was monitored using bioluminescence (Fig. 9 D). $5 \mathrm{~d}$ after transplantation, mice were divided into two groups. One group was treated with vehicle and the other with MALTli\#2 ( $30 \mathrm{mg} / \mathrm{kg}$ twice daily) via oral gavage. MALTli\#2 treatment significantly reduced Cond2-driven lymphoma growth in vivo (Fig. 9, D and E). A similar reduction of tumor load was observed when MCL-like lymphoma-bearing NSG mice were treated with CPZ (Fig. S5, C-E). In conclusion, both B1 cells and Bla-derived MCL-like lymphoma cells could be targeted using two independent inhibitors of MALT1 protease activity.

Finally, in an effort to translate our findings to patients, we used MCL patient-derived xenografts (PDXs). First, we confirmed that MCL PDXs express higher levels of NF- $\kappa$ B pathway components, including BCL10, than PDXs from other B cell malignancies (Fig. $9 \mathrm{G}$ ). Subsequently, we treated an MCL PDX ex vivo with increasing concentrations of CPZ, MPZ, MLT-748, or MALTlï2 and found that this PDX was sensitive to all four MALT1 inhibitors. In conclusion, and in line with MCL patients (Dai et al., 2017), MCL-like Cond2driven murine lymphomas show high MALT1 protease activity. In addition, we provide the first evidence for pharmacological inhibition of MALT1 activity in vivo as an effective anti-MCL therapy.

\section{Discussion}

The majority of MCLs carry translocations involving CCND1 and have increased expression of the cell cycle regulator cyclin D1.
Nevertheless, $70 \%$ of the cyclin D1-negative MCL cases have CCND2 rearrangements (Martín-Garcia et al., 2019; Salaverria et al., 2013), and one case was reported with a rearrangement involving CCND3 (Wlodarska et al., 2008). Therefore, genetic evidence suggests that all D-type cyclins are capable of inducing MCL when aberrantly activated. To validate the oncogenic role of D-type cyclins in vivo, $E \mu$-Ccndl mice have previously been generated mimicking the typical $t(11 ; 14)$ resulting in cyclin D1 overexpression. Strikingly, these Cond1-overexpressing mice do not develop MCL (Bodrug et al., 1994; Lovec et al., 1994). Hence, there is a lack of physiologically relevant MCL models, which are needed in order to perform preclinical testing of novel drugs for this aggressive hematological malignancy. In an attempt to generate a murine model of MCL, we developed an R26-Ccnd2 model that enables conditional overexpression of cyclin D2, and we report, for the first time, that hematopoiesis-specific gain of a D-type cyclin alone is sufficient to spontaneously develop MCL-like lymphomas in mice. We believe that both cyclins D1 and D2 have a similar intrinsic oncogenic potential, but that the promotor/enhancer elements that drive them may determine tumorigenesis. In our R26-Ccnd2 mice, the transgene is expressed from the endogenous $R 26$ promoter leading to moderate ubiquitous expression in all Cre-expressing cells, including B1 cells (Fig. S1 B). Two independent $E \mu$-Ccndl models were made that shared the Ig heavy chain enhancer $\mathrm{E} \mu$ but had a different promoter, either a promoter from a mouse variable gene segment $\left(V_{H}\right.$ 186.2; Lovec et al., 1994) or the potent viral SR $\alpha$ 
A Chlorpromazine (CPZ)

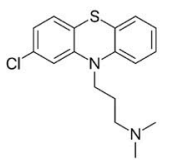

B

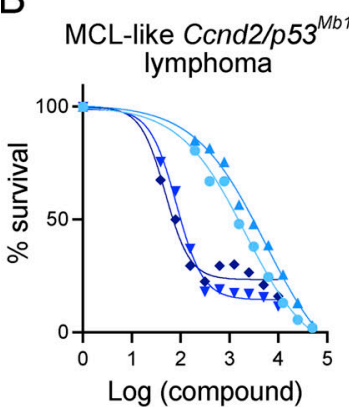

(compound)

$\rightarrow$ CPZ $\frac{\text { IC50 }}{2.12 \mu \mathrm{M}}$

- MPZ $5.37 \mu \mathrm{M}$

$\rightarrow \mathrm{MLT}-748 \quad 82 \mathrm{nM}$

$\rightarrow$ MALT1i\#2 49 nM
Mepazine (MPZ)

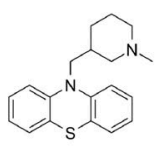

MLT-748

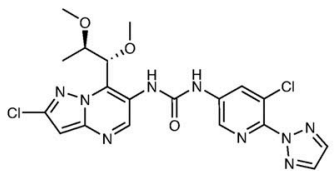

C

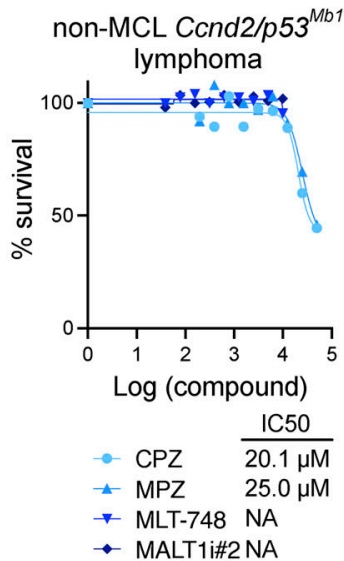

REC-1

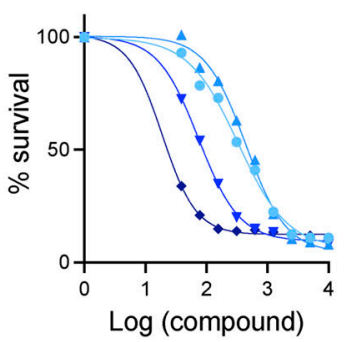

- CPZ $\frac{\text { IC50 }}{331 \mathrm{nM}}$

^- MPZ $442 \mathrm{nM}$

$\rightarrow$ MLT-748 $75 \mathrm{nM}$

- MALT1i\#2 $19 \mathrm{nM}$
MALT1i\#2

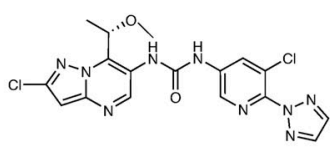

MINO

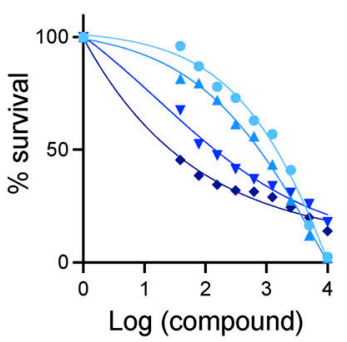

- CPZ $\frac{\mathrm{IC} 50}{1413 \mathrm{nM}}$

- MPZ $776 \mathrm{nM}$

$\rightarrow$ MLT-748 $126 \mathrm{nM}$

- MALT1i\#2 $25 \mathrm{nM}$

D

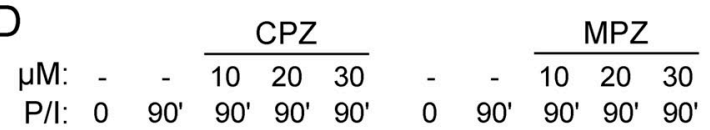
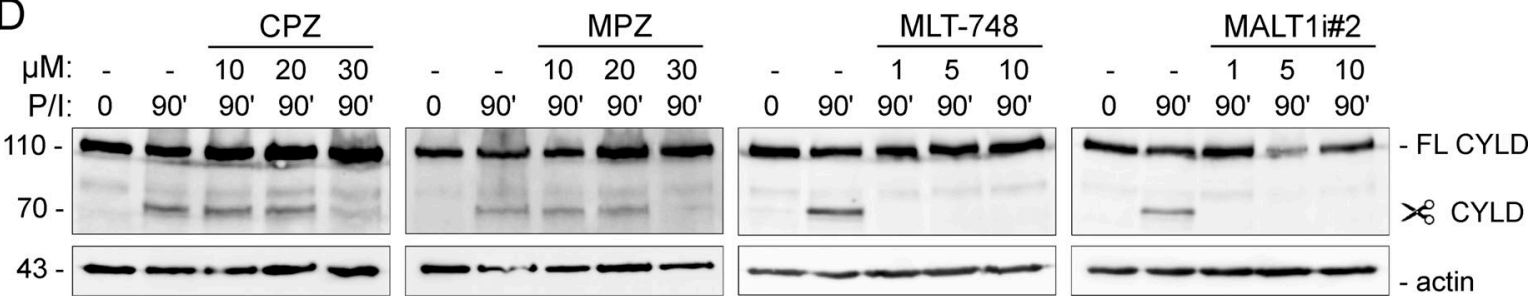

E
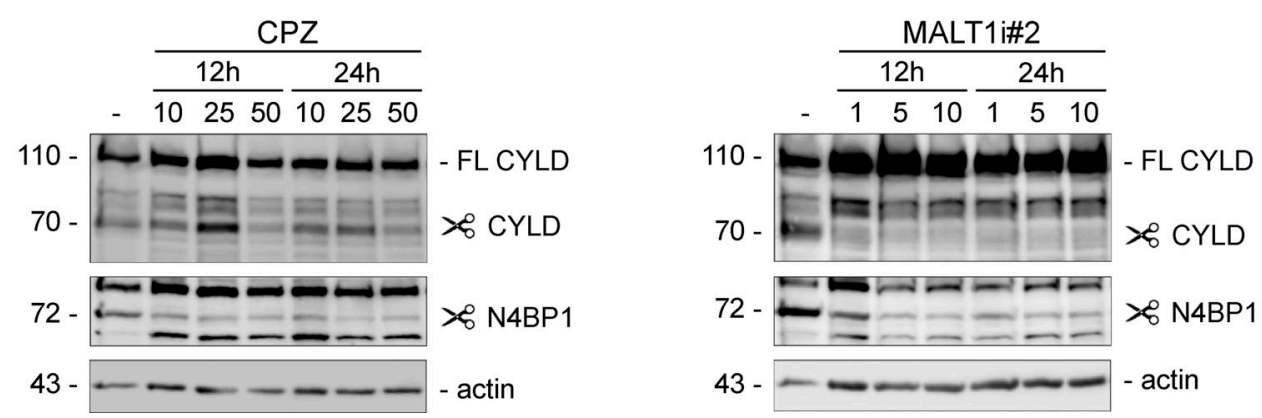

Figure 8. Targeting MALT1 protease activity in vitro in B1a/MCL-like murine lymphomas. (A) Chemical structure of four MALT1 inhibitors. (B and C) Dose-response curves of primary non-MCL or MCL-like Ccnd2/p53 $3^{\mathrm{Mb} 1}$ lymphomas (B) or human MCL cell lines REC-1 and MINO (C) that were treated with increasing concentrations of MALT1 inhibitors CPZ, MPZ, MLT-748, and MALT1i \#2. Half-maximal inhibitory concentration (IC50) values are depicted below the graphs. Experiments were performed twice. (D) Western blot analysis for cleaved CYLD levels in Jurkat cells that were inhibited with one of the four MALT1 inhibitors 30 min before a 90-min stimulation with PMA/ionomycin (P/I). Actin was used as loading control. (E) Western blot analysis for cleaved MALT1 substrates CYLD and N4BP1 in splenic cells from a C cnd2/p53 ${ }^{\mathrm{Mb1}}$ transplant (MCL-like \#2) treated with increasing concentrations of CPZ or MALT1i\#2 for 12 or $24 \mathrm{~h}$. Actin was used as a loading control. FL, full length. The molecular weight (kilodalton) in D and $\mathrm{E}$ is shown left of the blots.

promoter (Bodrug et al., 1994). One explanation might be that the core $\mathrm{E} \mu$ enhancer is not sufficient to drive adequate Condl levels to initiate oncogenesis. Indeed, it was recently shown that the IgH locus carries two superenhancers at both ends of the constant gene cluster, the $5^{\prime} \mathrm{E} \mu$ and $3^{\prime}$ regulatory regions, and demonstrated that the $3^{\prime}$ regulatory region controls $\mathrm{E} \mu$ in mature B cells, probably by IgH locus DNA looping (Saintamand et al., 2017). This enhancer cooperativity will not be present in
$E \mu$-Ccndl mice and may account for the relatively low levels of cyclin D1 in healthy tissues and the low or absent tumor formation in these mice (Bodrug et al., 1994; Lovec et al., 1994).

Another explanation for why $E \mu$-Ccndl mice fail to develop MCL in vivo could be because their enhancer/promoter is not sufficiently active in the cell of origin of MCL to promote transformation. We have found evidence that MCL-like cyclin D2-driven lymphomas have transcriptional and functional traits 
A
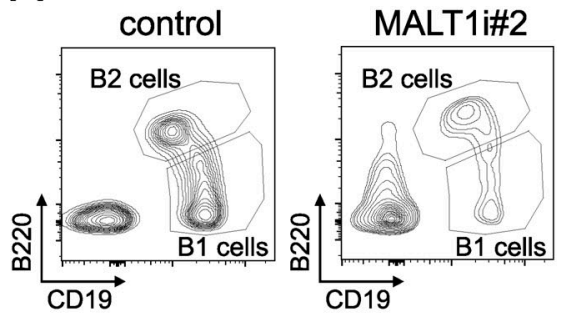

B

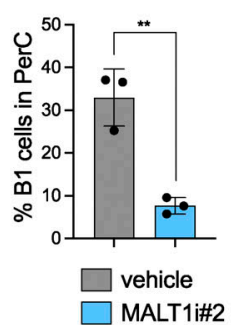

C

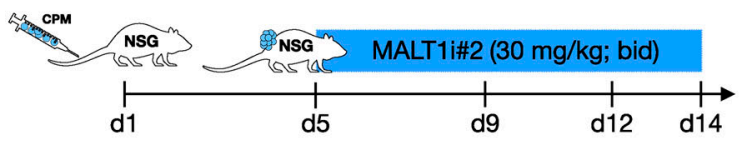

$\mathrm{D}$

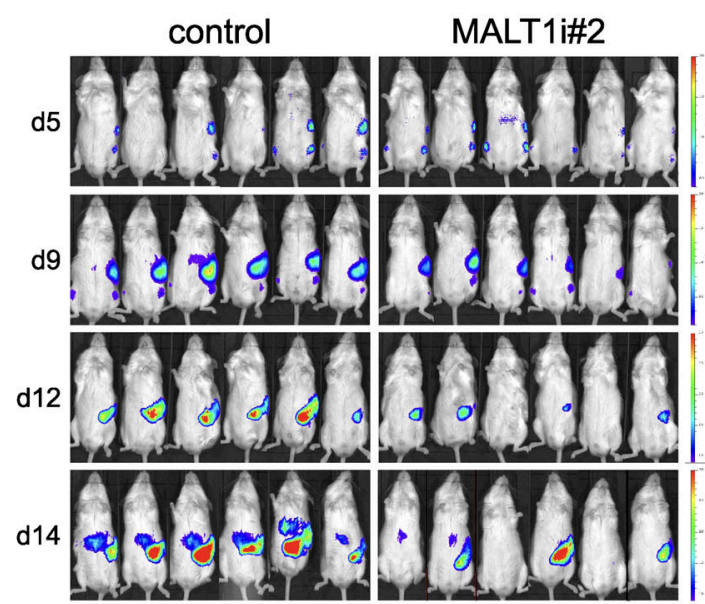

$E$

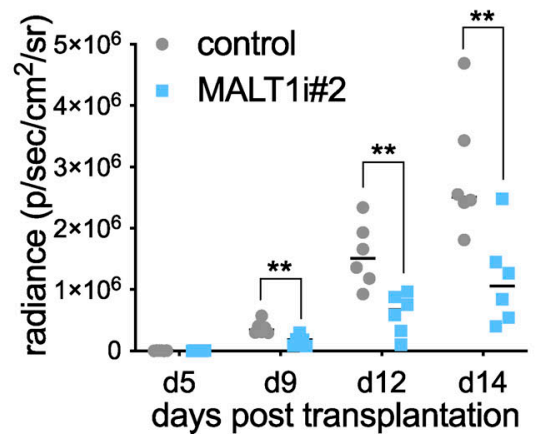

F

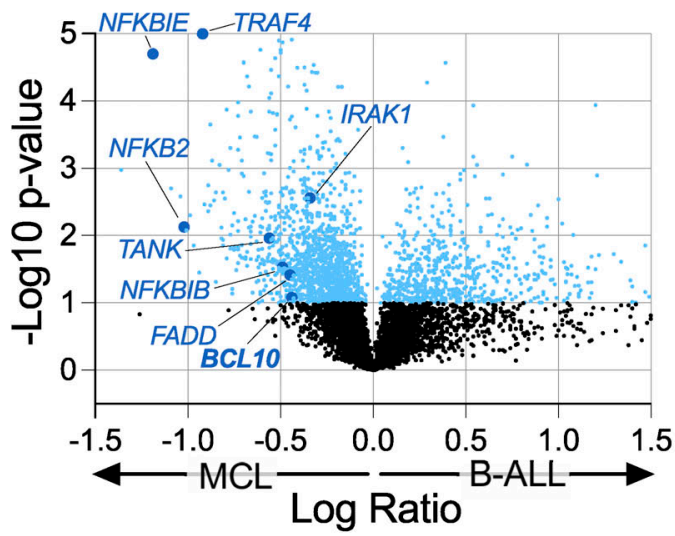

G

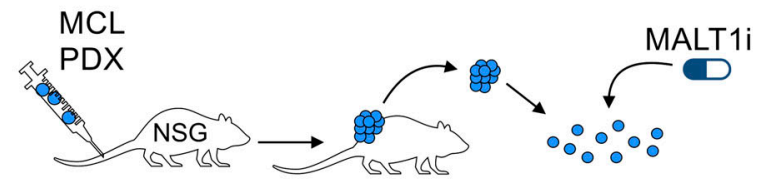

H MCL PDXs

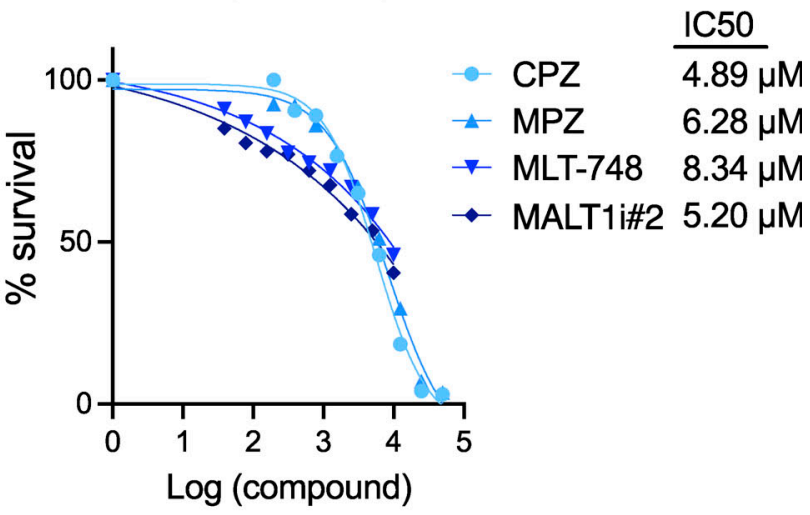

Figure 9. Targeting MALT1 protease activity in vivo in B1a/MCL-like murine lymphomas. (A) Flow cytometric analysis for CD19 and B220 in PerC B cells in wild-type C57BL/6 mice that were treated for 1 wk with PBS or $30 \mathrm{mg} / \mathrm{kg}$ (oral gavage twice daily) MALT1i\#2. (B) Graph depicting the number of peritoneal B1 cells in control and MALT1i\#2-treated mice $(n=3)$. Error bars represent the SD of three independent mice. (C) Scheme for i.v. transplantation of a Ccnd2/ p53 $3^{\mathrm{Mb1}}$ lymphoma with MALT1 activity (MCL-like \#2) in NSG mice and treatment schedule. bid, twice daily. (D) Bioluminescence over time in NSG mice that were transplanted and treated with either vehicle or MALT1i \#2. (E) Quantification of radiance from mice depicted in $D$. Day 9: ${ }^{* *}, P=0.0030 ;$ day $12:{ }^{* *}, P=$ 0.0034; day 14: **, $P=0.0077$. (F) Volcano plot showing differential gene expression between B cell acute lymphoblastic leukemia/lymphoma (B-ALL; $n=111$ ) and MCL $(n=17)$ PDXs. (G) Scheme for ex vivo treatment of MCL PDXs. (H) Dose-response curve for an MCL PDX that was treated with increasing concentrations of CPZ, MPZ, MLT-748, or MALT1i\#2. IC50, half-maximal inhibitory concentration; $\mathrm{p} / \mathrm{sec} / \mathrm{cm}^{2} / \mathrm{sr}$, photons per second per square centimeter per steradian.

of Bla B cells, suggesting that early life-derived Bla cells may be the cell origin of our murine Cond2-driven MCL. We validated Ccnd2 transgene expression in B1 cells from the PerC (Fig. 5 C). It is unknown whether $E \mu$-Ccndl mice express sufficient cyclin D1 in $\mathrm{B} 1$ cells to promote their transformation. It would be interesting to generate $R 26-C c n d 1$ mice in order to investigate if $C$ cndl, when expressed from the R26 promoter, would also be able to drive Bla/MCL-like lymphoma. The potential for $E \mu$-driven Condl expression to induce MCL-like lymphomas is supported by a recent report demonstrating that cyclin D1 expression is capable of inducing MCL-like lymphomas, but only in an enriched B1 cell population carrying a self-reactive ATA transgenic 
BCR (Hayakawa et al., 2018). Finally, cyclin D2 is the only D-type cyclin that is highly expressed in B1 cells, and, upon its genetic depletion in mice, B1 cells were abolished (Solvason et al., 2000). This suggests that cyclin D2 plays a pivotal role in murine B1 cell biology that cannot be readily compensated by its family members.

During murine B cell development, there is a switch from fetal to adult B lymphogenesis, which is controlled by Lin28b/ Let7, similar to the switch from fetal to definitive erythropoiesis (Hardy and Hayakawa, 2015; Kristiansen et al., 2018; Vanhee et al., 2019; Zhou et al., 2015). The early generated Bla cells persist during adult life and reside as a self-retaining population in body cavities, such as the PerC, but a small fraction is also present in the spleen. Their ability of long-term self-renewal due to self-antigen-driven BCR activation makes Bla cells an attractive target for oncogenic transformation. Bla cells have stereotyped IgH repertoires that are positively selected on self-antigens, including the phospholipid PtC, in a $\mathrm{T}$ cellindependent manner. Although $\mathrm{V}_{\mathrm{H}}$ 11-encoded PtC-binding $\mathrm{V}(\mathrm{D}) \mathrm{J}$ sequences are present at birth at very low frequencies, they increase tremendously as animals mature (Yang et al., 2015) and are especially enriched in $\mathrm{CD}^{+} \mathrm{B} 1$ cells (Vanhee et al., 2019). A subset of our MCL-like cyclin D2-driven lymphomas expressed $\mathrm{V}_{\mathrm{H}} 11$ - or $\mathrm{V}_{\mathrm{H}} 12$-encoded PtC-binding BCRs, and continuous exposure to its self-ligands resulted in BCR signaling pathway activation. Stereotyped BCRs are also observed in two mature naive $\mathrm{CD}^{+} \mathrm{B}$ cell lymphomas, namely MCL and CLL, indicating that Bla cells might be the cell of origin for both diseases (Chiorazzi and Ferrarini, 2011; Hadzidimitriou et al., 2011; Walsh et al., 2003). This was experimentally validated in mice because forced expression of a B1-specific BCR combined with either overexpression of Ccndl or TCL1 resulted in the formation of MCL- or CLL-like disease, respectively, in mice (Hayakawa et al., 2016; Hayakawa et al., 2018). Although expression of the MCLspecific oncogene Soxll in mice did not result in malignant transformation, it resulted in the specific expansion of Bla cells (Kuo et al., 2018). Altogether, these data provide additional support for the notion that B1 cells are likely to be the cell of origin in murine MCL. The existence of a human B1 cell orthologue remains controversial, and further studies are required (Descatoire et al., 2011; Griffin et al., 2011a; Griffin et al., 2011b; Perez-Andres et al., 2011). Nevertheless, many features of Bla cells have also been reported in MCL patients, such as secretion of natural IgM (Owen et al., 2000; Rymkiewicz et al., 2005), enhanced levels of pSTAT3 and IL-10 (Baran-Marszak et al., 2010), and biased BCR use (Hadzidimitriou et al., 2011; Walsh et al., 2003). This hints that a B cell with B1 cell characteristics might be the cell of origin in a subset of human MCL patients as well.

Because mice lacking fetally derived B1 cells are viable (Demeyer et al., 2016; Ruefli-Brasse et al., 2003; Ruland et al., 2003; Solvason et al., 2000), targeting B1-like specific pathways while sparing conventional B2 lymphocytes may represent an interesting novel therapeutic strategy for MCL. The MALT1 protease activity is crucial for the development of the innate-like marginal zone and B1 B cell populations, but it is dispensable for most other types of conventional BM-derived B2 cells
(Demeyer et al., 2016). We confirmed increased MALT1 protease activity in our Bla/MCL-like cyclin D2-driven murine model and could show that pharmacological inhibition of MALT1 protease activity, using two independent MALT1 inhibitors, MALTli\#2 and CPZ, indeed significantly reduced B1 cell populations.

To our knowledge, this Ccnd2-driven lymphoma model is the first spontaneous murine MCL-like model that recapitulates most pathophysiological aspects of human MCL. The introduction of the transgene luciferase reporter makes this model particularly amenable for preclinical drug testing. As such, we provide preclinical data using our transplantable MCL-like cyclin D2-driven model to show that inhibition of MALT1 activity is a potent anti-MCL therapy.

\section{Materials and methods Mouse experiments}

R26-Ccnd2 mice were generated according to a previously described optimized R26 targeting strategy (Pieters et al., 2019). To induce hematopoietic or B cell-specific expression, R26-Ccnd2 mice were crossed to Vav-iCre (JAX 008610; de Boer et al., 2003) and Mbl-Cre (JAX 020505; Hobeika et al., 2006) mice, respectively. Mice in which exons 2-10 of Trp53 were floxed were described before (Jonkers et al., 2001) and were crossed with $\mathrm{Mbl}-\mathrm{Cre}$ and R26-Ccnd2 mice. All experiments on mice were conducted according to institutional, national, and European animal regulations. All in vivo experiments were approved by the ethical committee for animal experimentation of the Faculty of Medicine and Health Sciences of Ghent University. Genotyping primers are listed in Table S3.

\section{Targeting vector assembly}

A recombinase-mediated cassette exchange (RMCE)-compatible targeting vector, $p R M C E-D V 3-C c n d 2$, was constructed by a stepwise multisite Gateway LR reaction, similar to one described before (Pieters et al., 2019). First, three entry vectors (pENTR L4R1 floxed stop, pENTR221 Ccnd2, pEntry 3' IRES-enhanced GFP (EGFP)/Luc; Haenebalcke et al., 2013a) were combined overnight, followed by a second overnight reaction together with the pRMCE-DV3 vector (Pieters et al., 2019; available at GeneCorner plasmid collection identifier LMBP 8189). Several colonies were obtained after transformation of $5 \mu \mathrm{l}$ of the LR reaction mixture into DH5a bacteria that were subsequently plated onto ampicillin-containing bacterial plates. To create the pENTR221 Ccnd2 vector, the open reading frame of Ccnd2 (BC049086) was amplified from the pYX-Asc-Ccnd2 vector (Mammalian Gene Collection) with primers AttB1-Ccnd2-F and AttB2-Ccnd2-R (listed in Table S3), followed by a Gateway BP reaction with the AttB-flanked PCR fragment and pDONR221 vector (Thermo Fisher Scientific). Three of five pRMCE-DV3Ccnd2 clones were confirmed by restriction enzyme digests and sequencing analysis.

\section{Mouse embryonic stem cell (mESC) culture, RMCE targeting, and validation}

A targeting vector that contained a floxed stop cassette followed by the Ccnd2 gene and an EGFP/luciferase reporter, which was 
subsequently targeted in mESCs using RMCE. G4 ROSALUC mESCs (Haenebalcke et al., 2013b) were cultured on gelatinized recipients containing MEFs (TgN (DR4)1 Jae strain) treated with mitomycin C (Sigma-Aldrich) as previously described (Pieters et al., 2016; Pieters et al., 2017). For the trap-coupled RMCE experiments, $50 \%$ confluent G4 ROSALUC mESCs (Haenebalcke et al., 2013b) were cotransfected with the pRMCE-DV3-Ccnd2 vector and an FlpE-expressing plasmid (pCAGGS-FlpE-IRESpuromycin-pA; Schaft et al., 2001) in a 1:1 ratio using Lipofectamine 2000 reagent (Thermo Fisher Scientific). G418 selection $(200 \mu \mathrm{g} / \mathrm{ml})$ was started $48 \mathrm{~h}$ after transfection. After 7-10 d, individual G418-resistant RMCE-targeted ESC colonies were observed and were further expanded. Eight colonies were picked and validated by PCR using primers ROSA26 F and Ins R (listed in Table S3). Correct integration was confirmed by PCR for all eight expanded mESC clones (100\% efficiency; Fig. S1 A) and confirmed that mESC targeting via RMCE is very efficient (Haenebalcke et al., 2013b; Pieters et al., 2016; Pieters et al., 2017). One of the correctly ROSA26-targeted ESC clones (clone 3) was subsequently aggregated with diploid embryonic day 2.5 Swiss embryos and gave rise to 10 high-grade chimeric animals. After germline transmission, the R26-C Cnd2 mouse line was established.

\section{Diploid embryo aggregation and mice}

The generation of chimeras by diploid embryo aggregation was reported previously (Pieters et al., 2016; Pieters et al., 2019). Briefly, zona pellucida free embryonic day 2.5 Swiss embryos were aggregated with clumps (7-10 cells) of targeted RMCE-DV3Ccnd2 mESCs using depression wells. Aggregates were cultured overnight in microdrops of KSOM with amino acids under mineral oil at $37^{\circ} \mathrm{C}$ in $95 \%$ air and $5 \% \mathrm{CO}_{2}$. The next day, blastocysts were transferred into the uteri of $2.5-\mathrm{d}$ postcoitum pseudopregnant B6CBAF1 females previously mated with vasectomized males. Chimeras were identified at birth by the presence of black eyes and later by agouti coat pigmentation. Established R26-Ccnd2 mice were backcrossed to C57BL/6.

\section{Ex vivo treatment, cell and PDX culture, and activation}

Fresh or frozen lymphoma cells (150,000 cells/well) and human MCL cell lines (25,000 cells/well) were cultured in RPMI 1640 with $10 \%$ FCS and supplemented with increasing concentrations of either CPZ or MPZ (Sigma-Aldrich), ibrutinib or MLT-748 (MedChemExpress), or MALTli\#2 (kind gift from the Center for Innovation and Stimulation of Drug Discovery Leuven, Leuven, Belgium; its synthesis is described in patent WO2015181747 [Pissot-Soldermann et al., 2015]), and cell viability was checked through ATP measurement by means of a CellTiter-Glo or RealTime-Glo viability assay (Promega). The Jurkat, REC1, and MINO cell lines were grown at $37^{\circ} \mathrm{C}$ in RPMI 1640 supplemented with $10 \%$ FCS and antibiotics. Jurkat cells were stimulated with 200 ng/ml PMA (Sigma-Aldrich) and $1 \mu \mathrm{M}$ ionomycin (Calbiochem). All PDX samples analyzed were obtained from the PRoXe consortium (Townsend et al., 2016) and were grown ex vivo in RPMI 1640 supplemented with 15\% FCS, penicillin (100 U/ml)streptomycin (100 mg/ml), $2 \mathrm{mM} \mathrm{L-glutamine} \mathrm{(Gibco),} 0.05 \mathrm{mM}$ 2-ME, $10 \mathrm{ng} / \mathrm{ml} \mathrm{IL-2,} 20 \mathrm{ng} / \mathrm{ml} \mathrm{IL-4,} 25 \mathrm{ng} / \mathrm{ml} \mathrm{IL-5,} 50 \mathrm{ng} / \mathrm{ml}$
IL-21 (PeproTech), $1 \mu \mathrm{g} / \mathrm{ml}$ anti-human CD40 antibody (clone G28.5; Tonbo Biosciences), and $10 \mu \mathrm{g} / \mathrm{ml}$ IgM Fab (115-006-020; Jackson ImmunoResearch).

\section{Histology and immunohistochemistry}

Tumors were fixed with $4 \%$ paraformaldehyde, embedded in paraffin, and sectioned. Tissue sections were deparaffinized and rehydrated. For histology, slides were stained with H\&E. For immunohistochemistry, antigen retrieval was performed by heating the sections in $10 \mathrm{mM}$ sodium citrate buffer ( $\mathrm{pH} \mathrm{6.0)}$ in an electric pressure cooker, after which the slides were permeabilized with $0.05 \%$ Tween 20 in PBS. Blocking of endogenous peroxidase occurred in $3 \% \mathrm{H}_{2} \mathrm{O}_{2}$ in methanol. Sections were then treated with $1 \%$ goat serum $/ 1 \%$ BSA in PBS, followed by incubation with primary anti-CD45R/B220 rat mAb (140452-85; eBioscience), anti-CD45 rat mAb (550539; BD Pharmingen), and anti-KI67 (Cell Signaling Technology) overnight at $4^{\circ} \mathrm{C}$. Biotin-conjugated secondary antibodies (Dako) were detected by the avidin-biotin complex (Vector Laboratories), amplified with a tyramide amplification system (PerkinElmer), and developed with diaminobenzidine (Dako).

\section{WES}

Genomic DNA was isolated from four Ccnd2 $2^{\text {Vav }}$ lymphomas and one spleen from a Cre-negative littermate control (reference DNA) using the DNeasy blood and tissue kit (Qiagen), and WES was performed by Novogene. In brief, after a quality control, 350-bp DNA libraries were made and sequenced (paired-end $150 \mathrm{bp}$ ) on an Illumina NovaSeq 6000 platform. Only exonic mutations (excluding single-nucleotide polymorphisms) with a mutation frequency $>0.30$ and that result in nonsynonymous or stop gain alterations were selected.

\section{QuantSeq 3' mRNA-seq and Bio-IT analysis}

Total RNA was isolated using an RNeasy Mini Kit (Qiagen) and converted into cDNA by using a QuantSeq 3' mRNA-Seq Reverse Library Prep Kit (Lexogen) according to the manufacturer's instructions to generate a compatible library for Illumina sequencing. Briefly, library generation was initiated by oligo(dT) priming for first-strand cDNA, which generated one fragment per transcript. The second-strand cDNA was subsequently synthesized using random primers. Illumina-specific linker sequences were introduced by the primer with barcoding indices for different samples. The quality of cDNA libraries was determined using a High Sensitivity DNA Assay 2100 Bioanalyzer (Agilent) for quality control analysis. Sequencing of the cDNA library with 75-bp single-end reads was performed using an Illumina HiSeq 2500 system. Reads were aligned to the reference genome GRCm38 using STAR-2.4.2a with default settings (Dobin et al., 2013). STAR was also used for gene expression quantification on the Ensembl GTF file version 84. Differential expression analysis was performed using DESeq2 in $\mathrm{R}$ (Love et al., 2014). Enrichment analysis was performed using Enrichr (Chen et al., 2013; Kuleshov et al., 2016) or gene set enrichment analysis (Subramanian et al., 2005). Differential gene expression between B lymphoblastic leukemia/lymphoma $(n=111)$ and MCL $(n=17)$ patient-derived samples was performed using 
default settings on the cBioPortal for Cancer Genomics (Cerami et al., 2012; Gao et al., 2013). All PDX samples analyzed were obtained from the PRoXe consortium (Townsend et al., 2016). Differential gene expression was considered significant at $\mathrm{q}$ values $<0.1$. Generalized cis-regulatory enrichment analysis was performed using i-cisTarget (Herrmann et al., 2012; Imrichová et al., 2015). Expression datasets from our murine lymphoma models are available in the Gene Expression Omnibus (accession no. GSE175568).

\section{Luciferase assay}

To measure luciferase activity, cells were lysed in Galacto-Star lysis buffer (Tropix), incubated with ONE-Glo substrate (Promega), and measured on a GloMax 96 microplate luminometer (Promega).

\section{Quantitative RT-PCR (qRT-PCR)}

Total RNA was isolated using an RNeasy Plus Mini Kit (Qiagen). cDNA was synthesized using the First Strand cDNA Synthesis Kit (Roche) with oligo(dT) primer starting from equal amounts of RNA as measured by a NanoDrop spectrophotometer (Thermo Fisher Scientific). qRT-PCR was performed using the SensiFast SYBR No-Rox Kit (Bioline) and monitored on a LightCycler 480 system (Roche). Gene expression was standardized against reference genes and analyzed using qbase+ (Biogazelle). All primers are listed in Table S3.

\section{Detecting secreted IgM levels}

To detect secreted IgM levels in vitro, $10^{6}$ lymphoma cells were cultured for $24 \mathrm{~h}$ in $200 \mu \mathrm{l}$ RPMI medium with $10 \%$ FCS. PB was collected on day 18 or day 13 , respectively, from moribund NSG mice that were transplanted with either $5 \times 10^{6}$ non-MCL (18821) or $10^{6}$ MCL-like (45080607) Ccnd2/p53 $3^{\mathrm{Mbl}}$ lymphoma cells. After centrifugation (10 min; 10,000 revolutions per minute; $4^{\circ} \mathrm{C}$ ), the supernatant was isolated, diluted (for in vitro: $500 \times$ and 5,000x; for serum: 20,000x and 200,000x) and measured using the Mouse/Rat IgM SimpleStep ELISA Kit (ab215085; Abcam).

\section{Western blotting}

Cells were lysed in radioimmunoprecipitation assay buffer (50 mM Tris-HCl, pH 7.6, 150 mM NaCl, 1 mM EDTA, 1\% [vol/ vol] NP-40, $0.5 \%$ sodium deoxycholate, and $0.1 \%$ SDS) with an additional $1 \%$ Triton X-100 plus phosphatase and protease inhibitors. $60 \mu \mathrm{g}$ protein lysate (in Laemmli buffer) was separated by SDS-PAGE on $10 \%$ polyacrylamide gels and blotted onto nitrocellulose transfer membranes (PerkinElmer) that were incubated with antibodies for specific protein detection: anti-CYLD (E10; Santa Cruz Biotechnology), anti-MALT1 (H-300; Santa Cruz Biotechnology), anti-BCL10 (sc-5273; Santa Cruz Biotechnology), and anit-N4BP1 (ab106649; Abcam). The polyclonal rabbit antibody specifically recognizing cleaved CYLD was produced by Eurogentec. The anti-cleaved BCL10 antibody was a gift from Dr. M. Baens (Catholic University of Leuven, Leuven, Belgium). Actin was used as a loading control with mouse HRPcoupled anti-actin mAb (sc-47778; Santa Cruz Biotechnology). Incubation with primary antibodies was followed by incubation with HRP-coupled secondary antibodies and detection using enhanced chemiluminescence (PerkinElmer Life Sciences). Developed blots were quantified with ImageJ software.

\section{Flow cytometry}

For flow cytometry, $5 \times 10^{6}$ cells were stained at $4^{\circ} \mathrm{C}$ in the dark with antibodies (Table S3) or rhodamine-containing 1,2-dioleoylsn-glycero-3-phosphocholine/cholesterol liposomes (FormuMax Scientific). Intracellular staining of Tdt and phospho-BTK was performed after fixing and permeabilizing the cells with a Foxp3 transcription factor-staining buffer set (eBioscience). The FIX \& PERM Cell Fixation and Permeabilization Kit (Thermo Fisher Scientific) was used for intracellular phospho-STAT3 staining. Cells were sorted on FACSAria II (BD Biosciences) and FACSAria Fusion (BD Biosciences) flow cytometers. Data were acquired on a cell analyzer (LSRFortessa; BD Biosciences) and analyzed using FlowJo software (FlowJo).

\section{Transplantation, bioluminescence, and MALT1i\#2 or CPZ treatment}

Immunocompromised NSG mice at 6-10 wk of age received an injection in the tail vein with $150 \mu \mathrm{l}$ PBS containing $5 \times 10^{6}$ $\mathrm{C}_{\mathrm{C} d 2^{\mathrm{Vav}}}$ or $10^{6} \mathrm{C} c n d 2 / \mathrm{p} 53^{\mathrm{Mbl}}$ tumor cells. At regular time points, the bioluminescence was measured using the IVIS Lumina II imaging system (PerkinElmer). Before imaging, the mice were injected i.p. with $200 \mu \mathrm{l}$ of a $15 \mathrm{mg} / \mathrm{ml}$ firefly D-luciferin potassium salt solution and anesthetized by inhalation of $5 \%$ isoflurane. The NSG mice were imaged $10 \mathrm{~min}$ after luciferin injection. The total bioluminescence signal in each mouse was calculated via the region of interest tool (total counts) in Living Image software (PerkinElmer). Upon engraftment, NSG mice were divided into two equal groups (based on radiance), followed by administration of vehicle or $10 \mathrm{mg} / \mathrm{kg}$ (days 11-18; CPZ in drinking water), $20 \mathrm{mg} / \mathrm{kg}$ (days 19-22; i.p.), or $50 \mathrm{mg} / \mathrm{kg}$ (days 22-24; i.p.) CPZ (Sigma-Aldrich) or $30 \mathrm{mg} / \mathrm{kg}$ MALTli\#2 (oral gavage twice daily) to the control and treatment groups, respectively. MALTli\#2 was dissolved in Kolliphor HS 15 (Sigma-Aldrich)/methylcellulose 0.5\% (VWR Chemicals; $2 / 98 \%$ ratio) under continuous stirring and protected from light (Van Nuffel et al., 2020).

\section{Statistical analysis}

GraphPad Prism version 7.0 was used for statistical analyses. The log-rank (Mantel-Cox) test was used to compare mouse groups. An unpaired $t$ test was used to analyze differences between genetic or phenotypic subgroups. $\mathrm{P}$ values $<0.05$ were considered statistically significant. All error bars represent the SEM. All in vitro experiments were run at least in duplicate. Combined score is defined as the Fisher's exact test $P$ value multiplied by the z-score for deviation from expected rank.

\section{Online supplemental material}

Fig. S1 shows the generation of R26-Ccnd2 mice, the validation of $\mathrm{C}_{\mathrm{C} d 2} 2^{\mathrm{Vav}}$ mice, and additional characterization of $\mathrm{Ccnd2} 2^{\mathrm{Vav}}$ lymphomas. Fig. S2 shows the transplantation of luciferasepositive $C_{c n d 2}{ }^{\text {Vav }}$ lymphomas, bioluminescence measurements over time, and characterization of primary $C_{c n d 2} 2^{\mathrm{Vav}}$ transplants. 
Fig. S3 shows the tumor spectrum, PB analysis, and spleen-to-body ratio of $p 53^{M b l}$ and $C c n d 2 / p 53^{M b l}$ mice. Fig. S4 shows the analysis of $B 1-$ specific BCRs in transplanted C cnd2/p53 ${ }^{M b 1}$ lymphomas. Fig. S5 shows in vivo targeting of wild-type B1 cells or B1-derived MCL-like lymphoma cells using the MALT1 inhibitor CPZ. Table S1 contains a list of single-nucleotide variants and indels from four Ccnd2 ${ }^{V a v}$ lymphomas. Table S2 contains a gene expression signature for $\mathrm{C}$ cnd2/p53 $3^{\mathrm{Mbl}} \mathrm{lym}$ phomas with or without an MCL-like immunophenotype. Table S3 contains primers for cloning, genotyping, and qRT-PCR, as well as information on antibodies that were used for flow cytometry.

\section{Acknowledgments}

We thank Pieter Adriaenssens, Jinke D'Hont, and Frédérique Van Rockeghem for technical assistance. We thank Elke De Bruyne for critical reading of the manuscript and helpful comments. We thank Prof. Neil Mabbott (University of Edinburgh, Edinburgh, UK) for sharing his B1-specific gene sets. The computational resources and services used in this work were provided by the Flemish Supercomputer Center funded by Fund for Scientific Research Flanders and the Flemish government.

This work was supported by the Fund for Scientific Research Flanders and the Ghent University Research Fund. S. Vanhee is a fundamental research postdoctoral fellow of the Research Foundation - Flanders (FWO-1244321N).

Author contributions: T. Pieters, S. Goossens, and P. Van Vlierberghe conceived and designed the experiments and wrote the paper. T. Pieters, S. T'Sas, A. Almeida, Y. Driege, M. Van Trimpont, J. Staal, K. Lemeire, L. Reunes, B. Lintermans, and T. Hochepied performed experiments. J. Roels, W. Van Loocke, J. Morscio, F. Matthijssens, F. Offner, and J. Van Dorpe analyzed data. J. Roels, W. Van Loocke, W. Daneels, M. Baens, A. Marchand, P. Chaltin, J. Staal, and R. Beyaert contributed reagents and analytical tools. S. Vanhee, J. Staal, J. Morscio, F. Matthijssens, F. Offner, R. Beyaert, and G. Berx discussed the results and critically reviewed the manuscript. S. Goossens and P. Van Vlierberghe directed and supervised the research. All authors approved the final manuscript.

Disclosures: R. Beyaert reported grants from Galapagos nv outside the submitted work; in addition, R. Beyaert had a patent to W009065897 issued. No other disclosures were reported.

Submitted: 24 October 2020

Revised: 24 February 2021

Accepted: 21 July 2021

\section{References}

Ban, T.A. 2007. Fifty years chlorpromazine: a historical perspective. Neuropsychiatr. Dis. Treat. 3:495-500.

Baran-Marszak, F., M. Boukhiar, S. Harel, C. Laguillier, C. Roger, R. Gressin, A. Martin, R. Fagard, N. Varin-Blank, F. Ajchenbaum-Cymbalista, and D. Ledoux. 2010. Constitutive and B-cell receptor-induced activation of STAT3 are important signaling pathways targeted by bortezomib in leukemic mantle cell lymphoma. Haematologica. 95:1865-1872. https:// doi.org/10.3324/haematol.2009.019745

Beà, S., R. Valdés-Mas, A. Navarro, I. Salaverria, D. Martín-Garcia, P. Jares, E. Giné, M. Pinyol, C. Royo, F. Nadeu, et al. 2013. Landscape of somatic mutations and clonal evolution in mantle cell lymphoma. Proc. Natl. Acad. Sci. USA. 110:18250-18255. https://doi.org/10.1073/pnas.1314608110

Beekman, R., V. Amador, and E. Campo. 2018. SOX11, a key oncogenic factor in mantle cell lymphoma. Curr. Opin. Hematol. 25:299-306. https://doi .org/10.1097/MOH.0000000000000434

Bergsagel, P.L., W.M. Kuehl, F. Zhan, J. Sawyer, B. Barlogie, and J. Shaughnessy Jr. 2005. Cyclin D dysregulation: an early and unifying pathogenic event in multiple myeloma. Blood. 106:296-303. https://doi.org/10 .1182/blood-2005-01-0034

Bodrug, S.E., B.J. Warner, M.L. Bath, G.J. Lindeman, A.W. Harris, and J.M. Adams. 1994. Cyclin D1 transgene impedes lymphocyte maturation and collaborates in lymphomagenesis with the myc gene. EMBO J. 13: 2124-2130. https://doi.org/10.1002/j.1460-2075.1994.tb06488.x

Bornancin, F., F. Renner, R. Touil, H. Sic, Y. Kolb, I. Touil-Allaoui, J.S. Rush, P.A. Smith, M. Bigaud, U. Junker-Walker, et al. 2015. Deficiency of MALT1 paracaspase activity results in unbalanced regulatory and effector $\mathrm{T}$ and $\mathrm{B}$ cell responses leading to multiorgan inflammation. J. Immunol. 194:3723-3734. https://doi.org/10.4049/jimmunol.1402254

Campo, E., and S. Rule. 2015. Mantle cell lymphoma: evolving management strategies. Blood. 125:48-55. https://doi.org/10.1182/blood-2014-05-521898

Campo, E., M. Raffeld, and E.S. Jaffe. 1999. Mantle-cell lymphoma. Semin. Hematol. 36:115-127.

Cerami, E., J. Gao, U. Dogrusoz, B.E. Gross, S.O. Sumer, B.A. Aksoy, A. Jacobsen, C.J. Byrne, M.L. Heuer, E. Larsson, et al. 2012. The cBio cancer genomics portal: an open platform for exploring multidimensional cancer genomics data. Cancer Discov. 2:401-404. https://doi.org/10.1158/ 2159-8290.CD-12-0095

Chen, E.Y., C.M. Tan, Y. Kou, Q. Duan, Z. Wang, G.V. Meirelles, N.R. Clark, and A. Ma'ayan. 2013. Enrichr: interactive and collaborative HTML5 gene list enrichment analysis tool. BMC Bioinformatics. 14:128. https:// doi.org/10.1186/1471-2105-14-128

Chiorazzi, N., and M. Ferrarini. 2011. Cellular origin(s) of chronic lymphocytic leukemia: cautionary notes and additional considerations and possibilities. Blood. 117:1781-1791. https://doi.org/10.1182/blood-2010-07 $-155663$

Dai, B., M. Grau, M. Juilland, P. Klener, E. Höring, J. Molinsky, G. Schimmack, S.M. Aukema, E. Hoster, N. Vogt, et al. 2017. B-cell receptor-driven MALT1 activity regulates MYC signaling in mantle cell lymphoma. Blood. 129:333-346. https://doi.org/10.1182/blood-2016-05-718775

de Boer, J., A. Williams, G. Skavdis, N. Harker, M. Coles, M. Tolaini, T. Norton, K. Williams, K. Roderick, A.J. Potocnik, and D. Kioussis. 2003. Transgenic mice with hematopoietic and lymphoid specific expression of Cre. Eur. J. Immunol. 33:314-325. https://doi.org/10.1002/immu.200310005

Demeyer, A., J. Staal, and R. Beyaert. 2016. Targeting MALT1 proteolytic activity in immunity, inflammation and disease: good or bad? Trends Mol. Med. 22:135-150. https://doi.org/10.1016/j.molmed.2015.12.004

Descatoire, M., J.C. Weill, C.A. Reynaud, and S. Weller. 2011. A human equivalent of mouse B-1 cells? J. Exp. Med. 208:2563-2564. https://doi .org/10.1084/jem.20112232

Dobin, A., C.A. Davis, F. Schlesinger, J. Drenkow, C. Zaleski, S. Jha, P. Batut, M. Chaisson, and T.R. Gingeras. 2013. STAR: ultrafast universal RNA-seq aligner. Bioinformatics. 29:15-21. https://doi.org/10 .1093/bioinformatics/bts635

Dorshkind, K., and E. Montecino-Rodriguez. 2007. Fetal B-cell lymphopoiesis and the emergence of B-1-cell potential. Nat. Rev. Immunol. 7:213-219. https://doi.org/10.1038/nri2019

Ehrenstein, M.R., and C.A. Notley. 2010. The importance of natural IgM: scavenger, protector and regulator. Nat. Rev. Immunol. 10:778-786. https://doi.org/10.1038/nri2849

Fernàndez, V., O. Salamero, B. Espinet, F. Solé, C. Royo, A. Navarro, F. Camacho, S. Beà, E. Hartmann, V. Amador, et al. 2010. Genomic and gene expression profiling defines indolent forms of mantle cell lymphoma. Cancer Res. 70:1408-1418. https://doi.org/10.1158/0008-5472.CAN-09 $-3419$

Fu, K., D.D. Weisenburger, T.C. Greiner, S. Dave, G. Wright, A. Rosenwald, M. Chiorazzi, J. Iqbal, S. Gesk, R. Siebert, et al. Lymphoma/Leukemia Molecular Profiling Project. 2005. Cyclin D1-negative mantle cell lymphoma: a clinicopathologic study based on gene expression profiling. Blood. 106:4315-4321. https://doi.org/10.1182/blood-2005-04-1753

Gao, J., B.A. Aksoy, U. Dogrusoz, G. Dresdner, B. Gross, S.O. Sumer, Y. Sun, A. Jacobsen, R. Sinha, E. Larsson, et al. 2013. Integrative analysis of complex cancer genomics and clinical profiles using the cBioPortal. Sci. Signal. 6:pl1. https://doi.org/10.1126/scisignal.2004088

Gewies, A., O. Gorka, H. Bergmann, K. Pechloff, F. Petermann, K.M. Jeltsch, M. Rudelius, M. Kriegsmann, W. Weichert, M. Horsch, et al. 2014. 
Uncoupling Malt1 threshold function from paracaspase activity results in destructive autoimmune inflammation. Cell Rep. 9:1292-1305. https://doi.org/10.1016/j.celrep.2014.10.044

Graf, R., J. Seagal, K.L. Otipoby, K.P. Lam, S. Ayoub, B. Zhang, S. Sander, V.T. $\mathrm{Chu}$, and K. Rajewsky. 2019. BCR-dependent lineage plasticity in mature B cells. Science. 363:748-753. https://doi.org/10.1126/science .aau8475

Greiner, T.C., M.J. Moynihan, W.C. Chan, D.M. Lytle, A. Pedersen, J.R. Anderson, and D.D. Weisenburger. 1996. p53 mutations in mantle cell lymphoma are associated with variant cytology and predict a poor prognosis. Blood. 87:4302-4310. https://doi.org/10.1182/blood.V87.10 .4302.bloodjournal87104302

Greiner, T.C., C. Dasgupta, V.V. Ho, D.D. Weisenburger, L.M. Smith, J.C. Lynch, J.M. Vose, K. Fu, J.O. Armitage, R.M. Braziel, et al. 2006. Mutation and genomic deletion status of ataxia telangiectasia mutated (ATM) and p53 confer specific gene expression profiles in mantle cell lymphoma. Proc. Natl. Acad. Sci. USA. 103:2352-2357. https://doi.org/10 $.1073 /$ pnas. 0510441103

Griffin, D.O., N.E. Holodick, and T.L. Rothstein. 2011a. Human B1 cells are CD3:- A reply to "A human equivalent of mouse B-1 cells?" and "The nature of circulating CD27 ${ }^{+}$CD $43^{+}$B cells". J. Exp. Med. 208:2566-2569. https://doi.org/10.1084/jem.20111761

Griffin, D.O., N.E. Holodick, and T.L. Rothstein. 2011b. Human B1 cells in umbilical cord and adult peripheral blood express the novel phenotype CD20+ CD27+ CD43+ CD70- J. Exp. Med. 208:67-80. https://doi.org/10 $.1084 /$ jem.20101499

Hadzidimitriou, A., A. Agathangelidis, N. Darzentas, F. Murray, M.H. DelfauLarue, L.B. Pedersen, A.N. Lopez, A. Dagklis, P. Rombout, K. Beldjord, et al. 2011. Is there a role for antigen selection in mantle cell lymphoma? Immunogenetic support from a series of 807 cases. Blood. 118: 3088-3095. https://doi.org/10.1182/blood-2011-03-343434

Haenebalcke, L., S. Goossens, P. Dierickx, S. Bartunkova, J. D'Hont, K. Haigh, T. Hochepied, D. Wirth, A. Nagy, and J.J. Haigh. 2013a. The ROSA26iPSC mouse: a conditional, inducible, and exchangeable resource for studying cellular (De)differentiation. Cell Rep. 3:335-341. https://doi .org/10.1016/j.celrep.2013.01.016

Haenebalcke, L., S. Goossens, M. Naessens, N. Kruse, M. Farhang Ghahremani, S. Bartunkova, K. Haigh, T. Pieters, P. Dierickx, B. Drogat, et al 2013b. Efficient ROSA26-based conditional and/or inducible transgenesis using RMCE-compatible F1 hybrid mouse embryonic stem cells. Stem Cell Rev. Rep. 9:774-785. https://doi.org/10.1007/s12015-013-9458-z

Hans, C.P., D.D. Weisenburger, T.C. Greiner, W.C. Chan, P. Aoun, G.T. Cochran, Z. Pan, L.M. Smith, J.C. Lynch, R.G. Bociek, et al. 2005. Expression of PKC- $\beta$ or cyclin D2 predicts for inferior survival in diffuse large B-cell lymphoma. Mod. Pathol. 18:1377-1384. https://doi.org/10 $.1038 /$ modpathol.3800434

Hardy, R.R., and K. Hayakawa. 2015. Perspectives on fetal derived CD5 ${ }^{+} B 1$ B cells. Eur. J. Immunol. 45:2978-2984. https://doi.org/10.1002/eji .201445146

Hayakawa, K., A.M. Formica, J. Brill-Dashoff, S.A. Shinton, D. Ichikawa, Y Zhou, H.C. Morse III, and R.R. Hardy. 2016. Early generated B1 B cells with restricted BCRs become chronic lymphocytic leukemia with continued c-Myc and low Bmf expression. J. Exp. Med. 213:3007-3024. https://doi.org/10.1084/jem.20160712

Hayakawa, K., A.M. Formica, Y. Nakao, D. Ichikawa, S.A. Shinton, J. BrillDashoff, M.R. Smith, H.C. Morse III, and R.R. Hardy. 2018. Early generated B-1-derived B cells have the capacity to progress to become mantle cell lymphoma-like neoplasia in aged mice. J. Immunol. 201: 804-813. https://doi.org/10.4049/jimmunol.1800400

Hernandez, L., T. Fest, M. Cazorla, J. Teruya-Feldstein, F. Bosch, M.A. Peinado, M.A. Piris, E. Montserrat, A. Cardesa, E.S. Jaffe, et al. 1996. p53 gene mutations and protein overexpression are associated with aggressive variants of mantle cell lymphomas. Blood. 87:3351-3359. https://doi.org/10.1182/blood.V87.8.3351.bloodjournal8783351

Herrmann, C., B. Van de Sande, D. Potier, and S. Aerts. 2012. i-cisTarget: an integrative genomics method for the prediction of regulatory features and cis-regulatory modules. Nucleic Acids Res. 40:e114. https://doi.org/10 $.1093 /$ nar/gks543

Hobeika, E., S. Thiemann, B. Storch, H. Jumaa, P.J. Nielsen, R. Pelanda, and M. Reth. 2006. Testing gene function early in the $B$ cell lineage in mbl-cre mice. Proc. Natl. Acad. Sci. USA. 103:13789-13794. https://doi.org/10 $.1073 /$ pnas. 0605944103

Hurt, E.M., A. Wiestner, A. Rosenwald, A.L. Shaffer, E. Campo, T. Grogan, P.L. Bergsagel, W.M. Kuehl, and L.M. Staudt. 2004. Overexpression of c-maf is a frequent oncogenic event in multiple myeloma that promotes proliferation and pathological interactions with bone marrow stroma. Cancer Cell. 5:191-199. https://doi.org/10.1016/S1535-6108(04)00019-4

Imrichová, H., G. Hulselmans, Z.K. Atak, D. Potier, and S. Aerts. 2015. i-cisTarget 2015 update: generalized cis-regulatory enrichment analysis in human, mouse and fly. Nucleic Acids Res. 43(W1):W57-W64. https:// doi.org/10.1093/nar/gkv395

Jacobs, K.A., G. André-Grégoire, C. Maghe, A. Thys, Y. Li, E. Harford-Wright, K. Trillet, T. Douanne, C. Alves Nicolau, J.S. Frénel, et al. 2020. Paracaspase MALT1 regulates glioma cell survival by controlling endolysosome homeostasis. EMBO J. 39:e102030. https://doi.org/10.15252/ embj.2019102030

Jares, P., D. Colomer, and E. Campo. 2007. Genetic and molecular pathogenesis of mantle cell lymphoma: perspectives for new targeted therapeutics. Nat. Rev. Cancer. 7:750-762. https://doi.org/10.1038/nrc2230

Jares, P., D. Colomer, and E. Campo. 2012. Molecular pathogenesis of mantle cell lymphoma. J. Clin. Invest. 122:3416-3423. https://doi.org/10.1172/ JCI61272

Jonkers, J., R. Meuwissen, H. van der Gulden, H. Peterse, M. van der Valk, and A. Berns. 2001. Synergistic tumor suppressor activity of BRCA2 and p53 in a conditional mouse model for breast cancer. Nat. Genet. 29:418-425. https://doi.org/10.1038/ng747

Katz, S.G., J.L. Labelle, H. Meng, R.P. Valeriano, J.K. Fisher, H. Sun, S.J. Rodig S.H. Kleinstein, and L.D. Walensky. 2014. Mantle cell lymphoma in cyclin D1 transgenic mice with Bim-deficient B cells. Blood. 123:884-893. https://doi.org/10.1182/blood-2013-04-499079

Kristiansen, T.A., S. Vanhee, and J. Yuan. 2018. The influence of developmental timing on B cell diversity. Curr. Opin. Immunol. 51:7-13. https:// doi.org/10.1016/j.coi.2017.12.005

Kuleshov, M.V., M.R. Jones, A.D. Rouillard, N.F. Fernandez, Q. Duan, Z. Wang, S. Koplev, S.L. Jenkins, K.M. Jagodnik, A. Lachmann, et al. 2016. Enrichr: a comprehensive gene set enrichment analysis web server 2016 update. Nucleic Acids Res. 44(W1):W90-W97. https://doi.org/10 .1093/nar/gkw377

Kuo, P.Y., S.S. Jatiani, A.H. Rahman, D. Edwards, Z. Jiang, K. Ahr, D. Perumal, V.V. Leshchenko, J. Brody, R. Shaknovich, et al. 2018. SOX11 augments BCR signaling to drive MCL-like tumor development. Blood. 131: 2247-2255. https://doi.org/10.1182/blood-2018-02-832535

Love, M.I., W. Huber, and S. Anders. 2014. Moderated estimation of fold change and dispersion for RNA-seq data with DESeq2. Genome Biol. 15: 550. https://doi.org/10.1186/s13059-014-0550-8

Lovec, H., A. Grzeschiczek, M.B. Kowalski, and T. Möröy. 1994. Cyclin D1/bcl1 cooperates with myc genes in the generation of B-cell lymphoma in transgenic mice. EMBO J. 13:3487-3495. https://doi.org/10.1002/j.1460 -2075.1994.tb06655.x

Mabbott, N.A., and D. Gray. 2014. Identification of co-expressed gene signatures in mouse B1, marginal zone and B2 B-cell populations. Immunology. 141:79-95. https://doi.org/10.1111/imm.12171

Martín-Garcia, D., A. Navarro, R. Valdés-Mas, G. Clot, J. Gutiérrez-Abril, M. Prieto, I. Ribera-Cortada, R. Woroniecka, G. Rymkiewicz, S. Bens, et al. 2019. CCND2 and CCND3 hijack immunoglobulin light-chain enhancers in cyclin $\mathrm{D1}^{-}$mantle cell lymphoma. Blood. 133:940-951. https://doi.org/ 10.1182/blood-2018-07-862151

Miller, R. 2009a. Mechanisms of action of antipsychotic drugs of different classes, refractoriness to therapeutic effects of classical neuroleptics, and individual variation in sensitivity to their actions: Part I. Curr. Neuropharmacol. 7:302-314. https://doi.org/10.2174/157015909790031229

Miller, R. 2009b. Mechanisms of action of antipsychotic drugs of different classes, refractoriness to therapeutic effects of classical neuroleptics, and individual variation in sensitivity to their actions: Part II. Curr. Neuropharmacol. 7:315-330. https://doi.org/10.2174/157015909790031184

Mozos, A., C. Royo, E. Hartmann, D. De Jong, C. Baró, A. Valera, K. Fu, D.D. Weisenburger, J. Delabie, S.S. Chuang, et al. 2009. SOX11 expression is highly specific for mantle cell lymphoma and identifies the cyclin D1negative subtype. Haematologica. 94:1555-1562. https://doi.org/10.3324/ haematol.2009.010264

Musgrove, E.A., C.E. Caldon, J. Barraclough, A. Stone, and R.L. Sutherland. 2011. Cyclin D as a therapeutic target in cancer. Nat. Rev. Cancer. 11: 558-572. https://doi.org/10.1038/nrc3090

Nadeu, F., D. Martin-Garcia, G. Clot, A. Díaz-Navarro, M. Duran-Ferrer, A. Navarro, R. Vilarrasa-Blasi, M. Kulis, R. Royo, J. Gutiérrez-Abril, et al. 2020. Genomic and epigenomic insights into the origin, pathogenesis, and clinical behavior of mantle cell lymphoma subtypes. Blood. 136: 1419-1432. https://doi.org/10.1182/blood.2020005289

Nagel, D., S. Spranger, M. Vincendeau, M. Grau, S. Raffegerst, B. Kloo, D. Hlahla, M. Neuenschwander, J. Peter von Kries, K. Hadian, et al. 2012. 
Pharmacologic inhibition of MALT1 protease by phenothiazines as a therapeutic approach for the treatment of aggressive ABC-DLBCL. Cancer Cell. 22:825-837. https://doi.org/10.1016/j.ccr.2012.11.002

Owen, R.G., L.A. Parapia, J. Higginson, S.A. Misbah, J.A. Child, G.J. Morgan, and A.S. Jack. 2000. Clinicopathological correlates of IgM paraproteinemias. Clin. Lymphoma. 1:39-43, discussion: 44-45. https://doi .org/10.3816/CLM.2000.n.003

Palmero, I., A. Holder, A.J. Sinclair, C. Dickson, and G. Peters. 1993. Cyclins D1 and D2 are differentially expressed in human B-lymphoid cell lines. Oncogene. 8:1049-1054.

Perez-Andres, M., C. Grosserichter-Wagener, C. Teodosio, J.J. van Dongen, A. Orfao, and M.C. van Zelm. 2011. The nature of circulating $\mathrm{CD} 27^{+} \mathrm{CD} 43^{+}$ B cells. J. Exp. Med. 208:2565-2566. https://doi.org/10.1084/jem .20112203

Pieters, T., S. Goossens, L. Haenebalcke, V. Andries, A. Stryjewska, R. De Rycke, K. Lemeire, T. Hochepied, D. Huylebroeck, G. Berx, et al. 2016. p120 catenin-mediated stabilization of E-cadherin is essential for primitive endoderm specification. PLoS Genet. 12:e1006243. https://doi .org/10.1371/journal.pgen.1006243

Pieters, T., L. Haenebalcke, K. Bruneel, N. Vandamme, T. Hochepied, J. van Hengel, D. Wirth, G. Berx, J.J. Haigh, F. van Roy, and S. Goossens. 2017. Structure-function studies in mouse embryonic stem cells using recombinase-mediated cassette exchange. J. Vis. Exp. (122):e55575. https://doi.org/10.3791/55575

Pieters, T., S. T'Sas, L. Demoen, A. Almeida, L. Haenebalcke, F. Matthijssens, K. Lemeire, J. D’Hont, F. Van Rockeghem, T. Hochepied, et al. 2019. Novel strategy for rapid functional in vivo validation of oncogenic drivers in haematological malignancies. Sci. Rep. 9:10577. https://doi .org/10.1038/s41598-019-46853-x

Pissot-Soldermann, C., J. Quancard, A. Schlapbach, O. Simic, M. TintelnotBlomley, and T. Zoller. 2015. Novel pyrazolo pyrimidine derivates and their use as MALT1 inhibitors. World Intellectual Property Organization patent WO2015181747, filed May 27, 2015, and issued December 3, 2015.

Quancard, J., T. Klein, S.Y. Fung, M. Renatus, N. Hughes, L. Israël, J.J. Priatel, S. Kang, M.A. Blank, R.I. Viner, et al. 2019. An allosteric MALT1 inhibitor is a molecular corrector rescuing function in an immunodeficient patient. Nat. Chem. Biol. 15:304-313. https://doi.org/10.1038/ s41589-018-0222-1

Rebeaud, F., S. Hailfinger, A. Posevitz-Fejfar, M. Tapernoux, R. Moser, D. Rueda, O. Gaide, M. Guzzardi, E.M. Iancu, N. Rufer, et al. 2008. The proteolytic activity of the paracaspase MALTl is key in T cell activation. Nat. Immunol. 9:272-281. https://doi.org/10.1038/nil568

Ruefli-Brasse, A.A., D.M. French, and V.M. Dixit. 2003. Regulation of NFkappaB-dependent lymphocyte activation and development by paracaspase. Science. 302:1581-1584. https://doi.org/10.1126/science.1090769

Ruland, J., G.S. Duncan, A. Wakeham, and T.W. Mak. 2003. Differential requirement for Malt1 in $\mathrm{T}$ and $\mathrm{B}$ cell antigen receptor signaling. Immunity. 19:749-758. https://doi.org/10.1016/S1074-7613(03)00293-0

Rymkiewicz, G., M. Gos, K. Błachnio, R. Woroniecka, P. Swoboda, B. Pieńkowska-Grela, M. Kulińska, A. Borawska, P. Janik, and J. Walewski. 2005. Mantle cell lymphoma presenting with paraproteinemia. Med. Oncol. 22:319-323. https://doi.org/10.1385/MO:22:3:319

Saintamand, A., C. Vincent-Fabert, M. Marquet, N. Ghazzaui, V. Magnone, E. Pinaud, M. Cogné, and Y. Denizot. 2017. $E_{\mu}$ and 3'RR IgH enhancers show hierarchic unilateral dependence in mature B-cells. Sci. Rep. 7:442. https://doi.org/10.1038/s41598-017-00575-0

Salaverria, I., C. Royo, A. Carvajal-Cuenca, G. Clot, A. Navarro, A. Valera, J.Y. Song, R. Woroniecka, G. Rymkiewicz, W. Klapper, et al. 2013. CCND2 rearrangements are the most frequent genetic events in cyclin $\mathrm{D} 1^{-}-$ mantle cell lymphoma. Blood. 121:1394-1402. https://doi.org/10.1182/ blood-2012-08-452284

Schaft, J., R. Ashery-Padan, F. van der Hoeven, P. Gruss, and A.F. Stewart. 2001. Efficient FLP recombination in mouse ES cells and oocytes. Genesis. 31:6-10. https://doi.org/10.1002/gene.1076

Schlauderer, F., K. Lammens, D. Nagel, M. Vincendeau, A.C. Eitelhuber, S.H. Verhelst, D. Kling, A. Chrusciel, J. Ruland, D. Krappmann, and K.P. Hopfner. 2013. Structural analysis of phenothiazine derivatives as allosteric inhibitors of the MALT1 paracaspase. Angew. Chem. Int. Ed. Engl. 52:10384-10387. https://doi.org/10.1002/anie.201304290

Sherr, C.J., and J.M. Roberts. 2004. Living with or without cyclins and cyclindependent kinases. Genes Dev. 18:2699-2711. https://doi.org/10.1101/gad .1256504
Smith, M.R., I. Joshi, F. Jin, and T. Al-Saleem. 2006. Murine model for mantle cell lymphoma. Leukemia. 20:891-893. https://doi.org/10.1038/sj.leu .2404177

Solvason, N., W.W. Wu, D. Parry, D. Mahony, E.W. Lam, J. Glassford, G.G. Klaus, P. Sicinski, R. Weinberg, Y.J. Liu, et al. 2000. Cyclin D2 is essential for BCR-mediated proliferation and CD5 B cell development. Int. Immunol. 12:631-638. https://doi.org/10.1093/intimm/12.5.631

Staal, J., Y. Driege, T. Bekaert, A. Demeyer, D. Muyllaert, P. Van Damme, K. Gevaert, and R. Beyaert. 2011. T-cell receptor-induced JNK activation requires proteolytic inactivation of CYLD by MALT1. EMBO J. 30: 1742-1752. https://doi.org/10.1038/emboj.2011.85

Subramanian, A., P. Tamayo, V.K. Mootha, S. Mukherjee, B.L. Ebert, M.A. Gillette, A. Paulovich, S.L. Pomeroy, T.R. Golub, E.S. Lander, and J.P. Mesirov. 2005. Gene set enrichment analysis: a knowledge-based approach for interpreting genome-wide expression profiles. Proc. Natl. Acad. Sci. USA. 102:15545-15550. https://doi.org/10.1073/pnas.0506580102

Swerdlow, S.H., E. Campo, S.A. Pileri, N.L. Harris, H. Stein, R. Siebert, R. Advani, M. Ghielmini, G.A. Salles, A.D. Zelenetz, and E.S. Jaffe. 2016. The 2016 revision of the World Health Organization classification of lymphoid neoplasms. Blood. 127:2375-2390. https://doi.org/10.1182/ blood-2016-01-643569

Townsend, E.C., M.A. Murakami, A. Christodoulou, A.L. Christie, J. Köster, T.A. DeSouza, E.A. Morgan, S.P. Kallgren, H. Liu, S.C. Wu, et al. 2016. The public repository of xenografts enables discovery and randomized phase II-like trials in mice. Cancer Cell. 29:574-586. https://doi.org/10 .1016/j.ccell.2016.03.008

Van Nuffel, E., J. Staal, G. Baudelet, M. Haegman, Y. Driege, T. Hochepied, I.S Afonina, and R. Beyaert. 2020. MALT1 targeting suppresses CARD14induced psoriatic dermatitis in mice. EMBO Rep. 21:e49237. https://doi org/10.15252/embr.201949237

Vanhee, S., H. Åkerstrand, T.A. Kristiansen, S. Datta, G. Montano, S. Vergani, S. Lang, J. Ungerbäck, A. Doyle, K. Olsson, et al. 2019. Lin28b controls a neonatal to adult switch in B cell positive selection. Sci. Immunol. 4: eaax4453. https://doi.org/10.1126/sciimmunol.aax4453

Walsh, S.H., M. Thorsélius, A. Johnson, O. Söderberg, M. Jerkeman, E. Björck, I. Eriksson, U. Thunberg, O. Landgren, M. Ehinger, et al. 2003. Mutated $\mathrm{VH}$ genes and preferential VH3-21 use define new subsets of mantle cell lymphoma. Blood. 101:4047-4054. https://doi.org/10.1182/blood-2002 $-11-3479$

Wang, M.L., S. Rule, P. Martin, A. Goy, R. Auer, B.S. Kahl, W. Jurczak, R.H. Advani, J.E. Romaguera, M.E. Williams, et al. 2013. Targeting BTK with ibrutinib in relapsed or refractory mantle-cell lymphoma. N. Engl. J. Med. 369:507-516. https://doi.org/10.1056/NEJMoal306220

Winkler, D., C. Schneider, A. Kröber, L. Pasqualucci, P. Lichter, H. Döhner, and S. Stilgenbauer. 2005. Protein expression analysis of chromosome 12 candidate genes in chronic lymphocytic leukemia (CLL). Leukemia. 19:1211-1215. https://doi.org/10.1038/sj.leu.2403778

Wlodarska, I., D. Dierickx, V. Vanhentenrijk, K. Van Roosbroeck, H. Pospísilová, F. Minnei, G. Verhoef, J. Thomas, P. Vandenberghe, and C. De Wolf-Peeters. 2008. Translocations targeting CCND2, CCND3, and MYCN do occur in t(11;14)-negative mantle cell lymphomas. Blood. 111: 5683-5690. https://doi.org/10.1182/blood-2007-10-118794

Yamasoba, D., K. Sato, T. Ichinose, T. Imamura, L. Koepke, S. Joas, E. Reith, D. Hotter, N. Misawa, K. Akaki, et al. 2019. N4BP1 restricts HIV-1 and its inactivation by MALT1 promotes viral reactivation. Nat. Microbiol. 4: 1532-1544. https://doi.org/10.1038/s41564-019-0460-3

Yang, Y., C. Wang, Q. Yang, A.B. Kantor, H. Chu, E.E. Ghosn, G. Qin, S.K. Mazmanian, J. Han, and L.A. Herzenberg. 2015. Distinct mechanisms define murine B cell lineage immunoglobulin heavy chain (IgH) repertoires. eLife. 4:e09083. https://doi.org/10.7554/eLife.09083

Yu, J.W., S. Hoffman, A.M. Beal, A. Dykon, M.A. Ringenberg, A.C. Hughes, L. Dare, A.D. Anderson, J. Finger, V. Kasparcova, et al. 2015. MALT1 protease activity is required for innate and adaptive immune responses. PLoS One. 10:e0127083. https://doi.org/10.1371/journal.pone.0127083

Zhou, Y., Y.S. Li, S.R. Bandi, L. Tang, S.A. Shinton, K. Hayakawa, and R.R. Hardy. 2015. Lin28b promotes fetal B lymphopoiesis through the transcription factor Arid3a. J. Exp. Med. 212:569-580. https://doi.org/10 $.1084 /$ jem. 20141510

Zlamalikova, L., M. Moulis, D. Salek, J. Jarkovsky, J. Smarda, and J. Smardova. 2016. Expression of D-type cyclins in mantle cell and diffuse large B-cell lymphomas. Oncol. Rep. 35:2673-2680. https://doi.org/10.3892/or.2016 .4658 


\section{Supplemental material}


A
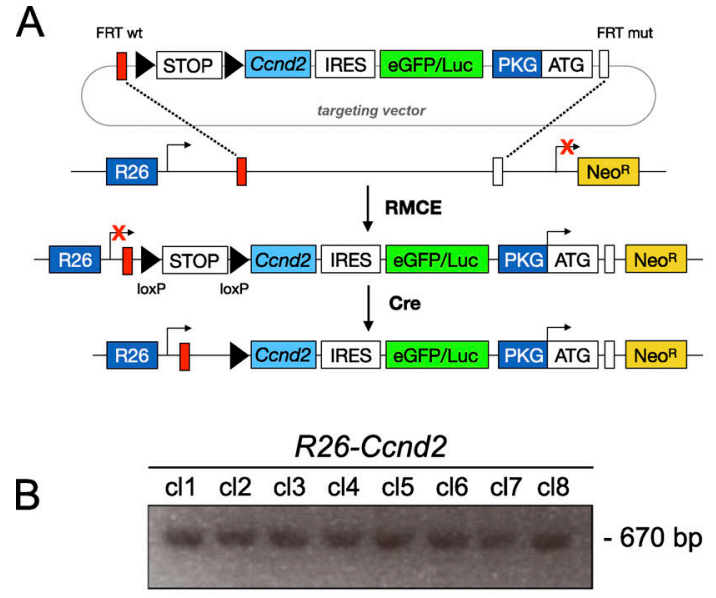

C

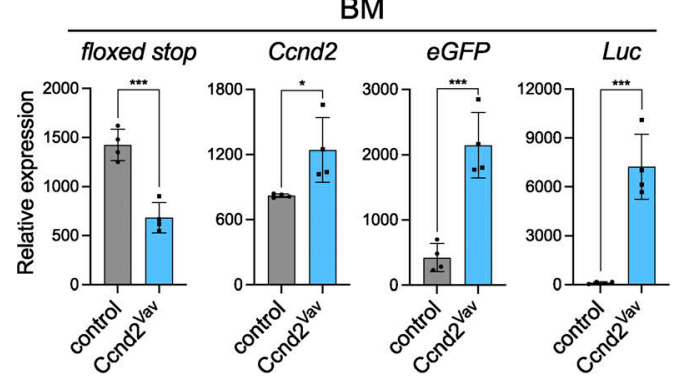

Spleen

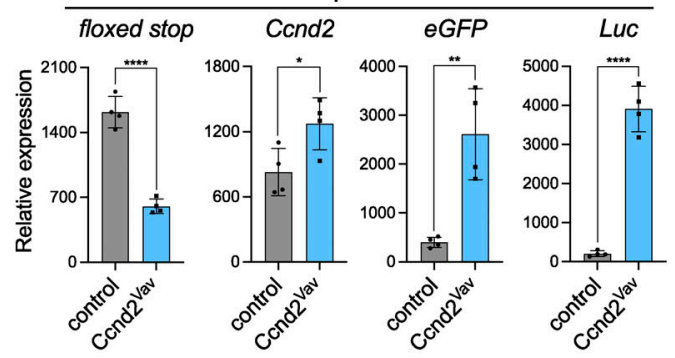

PerC

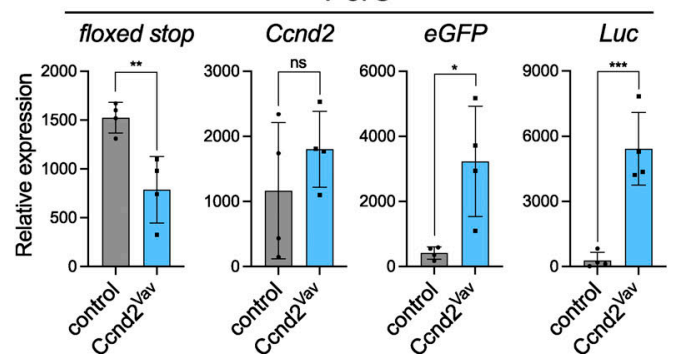

D
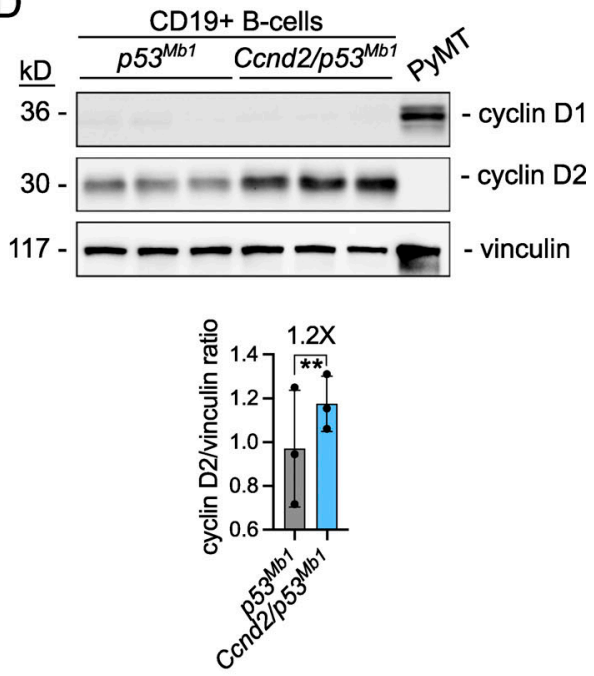

E

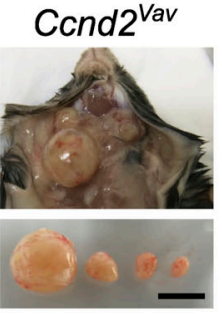

$\mathrm{F}$

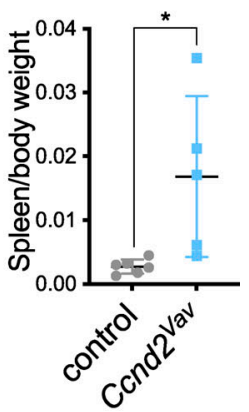

G

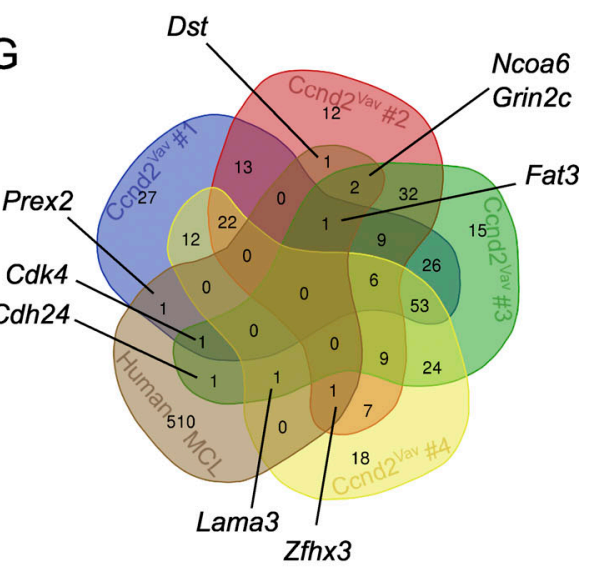

Figure S1. Generation and validation of R26-C cnd2 mice and analysis of $\boldsymbol{C} \mathbf{c n d 2} \mathbf{V}^{\mathbf{v a v}}$ lymphomas. (A) Schematic representation of $C \mathrm{cnd} 2$ targeting to the Rosa26 locus via RMCE in mESCs. Upon Cre-mediated recombination, the floxed stop cassette is removed and a bicistronic transgene transcript, encoding for cyclin D2 and the eGFP/Luciferase reporter, is expressed from the Rosa26 promoter. R26, ROSA26; IRES, independent ribosomal entry site; PKG, phosphoglycerate kinase 1; Neo ${ }^{R}$, neomycin resistance gene; FRT, flippase recognition target; Luc, luciferase. (B) Validation of targeted RMCE-DV3-Ccnd2 mESCs using PCR. (C) qRT-PCR analysis for Ccnd2, the floxed stop cassette and of EGFP/Luc on cells from BM, spleen or PerC of Ccnd2 ${ }^{\text {vav }}$ mice or Cre-negative controls (four mice/group). Error bars represent the SD of four independent mouse samples. ${ }^{*}, \mathrm{P}<0.05 ;{ }^{* *}, \mathrm{P}<0.01 ;{ }^{* * *}, \mathrm{P}<0.001 ;{ }^{* * *}, \mathrm{P}<0.0001$. (D) Western blot analysis for cyclin D1, cyclin D2, and vinculin (loading control) on CD19-enriched (MACS purification) BM B-cells from p53 $3^{M b 1}$ and C $\mathrm{cnd} 2 / \mathrm{p} 53^{\mathrm{Mb1}}$ mice. The cyclin D1-positive primary breast cancer cell line, derived from a polyomavirus middle T antigen (PyMT) mouse model, was taken as a positive control. Cyclin D2 bands were quantified and normalized against the loading control (bottom). There was a statistically significant increase in cyclin D2 levels (2.2-fold increase; **, $\mathrm{P}=0.0087$ ) in $\mathrm{C} c n d 2 / \mathrm{p} 53^{\mathrm{Mb1}}$ mice, compared to those in $\mathrm{p} 53^{\mathrm{Mb1}}$ mice. Error bars represent the SD of three independent mouse samples. (E) 36 wk-old $\mathrm{Ccnd2}^{\mathrm{Vav}}$ mouse with lymphomas in superficial cervical, parotid, and submandibular lymph nodes. (F) Graph depicting the spleen-to-body weight ratio in nonrecombined control and $C \mathrm{cnd} 2^{v a v}$ mice. ${ }^{*}, P=0.0220$. (G) Venn diagram showing unique and overlapping mutation that were found in four $C \mathrm{cnd} 2 \mathrm{Vav}$ lymphomas and human MCL patients (Beà et al., 2013). Healthy spleen cells from a littermate were used as control. 
A

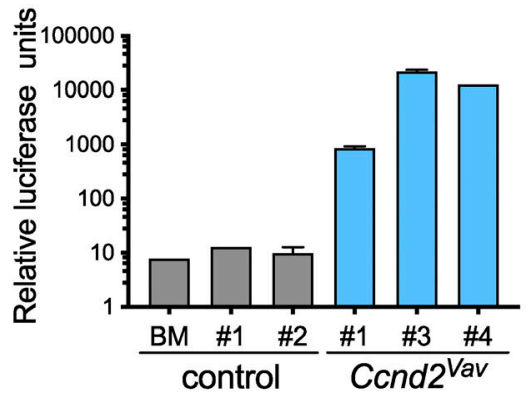

C
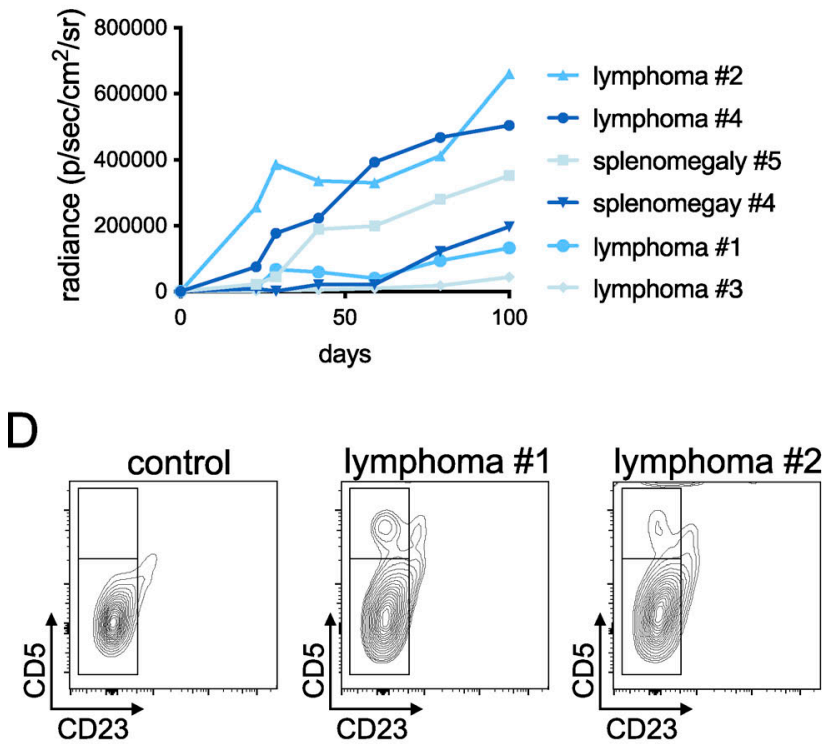

$E$

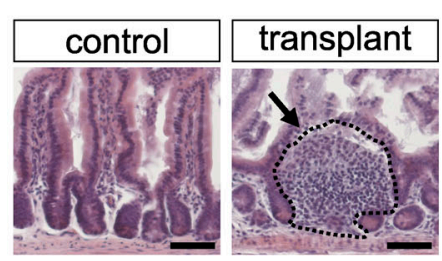

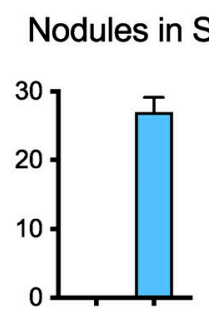

B
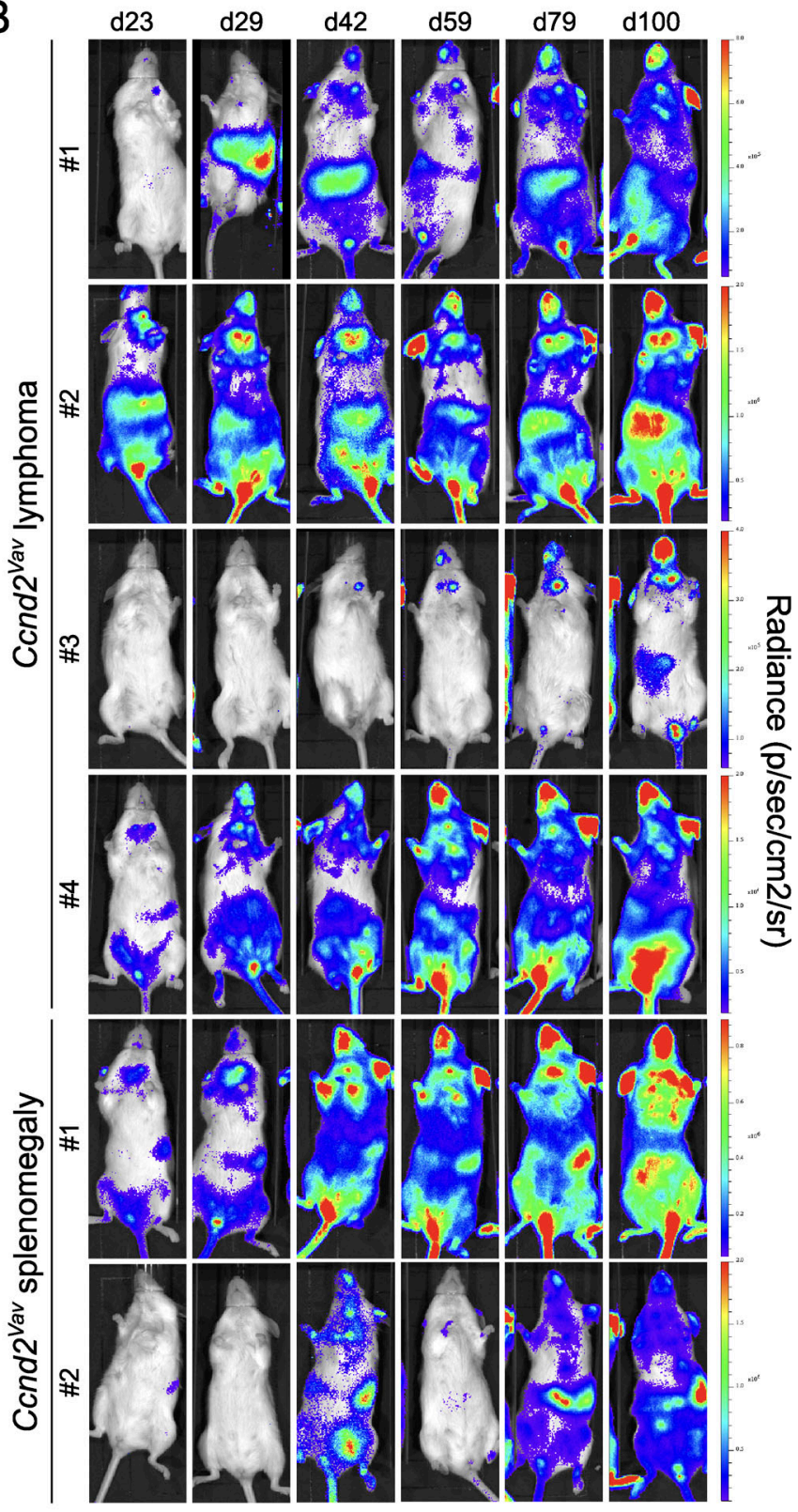

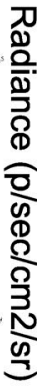

Figure S2. Transplantation of $C \mathbf{c n d 2} \mathbf{2}^{\text {vav }}$ lymphomas. (A) Luciferase reporter assay on healthy non-recombined littermate controls and $C \mathrm{cnd2}$ vav lymphomas. (B) Bioluminescence measured over time in immunocompromised NSG mice tail vein injected with $0.5-1.5 \times 10^{6}$ lymphoma or splenic tumor cells from Ccnd2vav mice. From all five Cond2 ${ }^{v a v}$ mice, lymphoma and/or splenomegaly cells were transplanted. After 1-2 mo, all murine MCL cells had engrafted and homed to relevant sites, such as the lymph nodes, liver, and spleen. After $100 \mathrm{~d}$, mice were sacrificed and tumor-containing organs were dissected. (C) Graph depicting radiance levels that are plotted over time for NSGs from B. (D) Flow cytometry analysis of transplanted cyclin D2-driven murine MCL. Single live CD45+ cells were analyzed for $\mathrm{CD} 5$ and $\mathrm{CD} 23$ and confirmed the presence of $\mathrm{MCL}$-like $\mathrm{CD} 19^{+} \mathrm{CD} 5^{+} \mathrm{CD} 23^{-}$cells in the affected organs. (E) H\&E-stained paraffin sections of small intestine (SI) of a control NSG and of an NSG that was transplanted with Cond2vav lymphoma cells. The arrow points to a tumor nodule (dashed line; left panel) and the total number of tumor nodules in the small intestine was quantified in both a control and a NSG that was transplanted with Ccnd2 $2^{v a v}$ lymphoma cells (right panel). Scale bar, $50 \mu \mathrm{M}$. Error bars represent SD. $\mathrm{p} / \mathrm{sec} / \mathrm{cm}^{2} / \mathrm{sr}$, photons per second per square centimeter per steradian. 

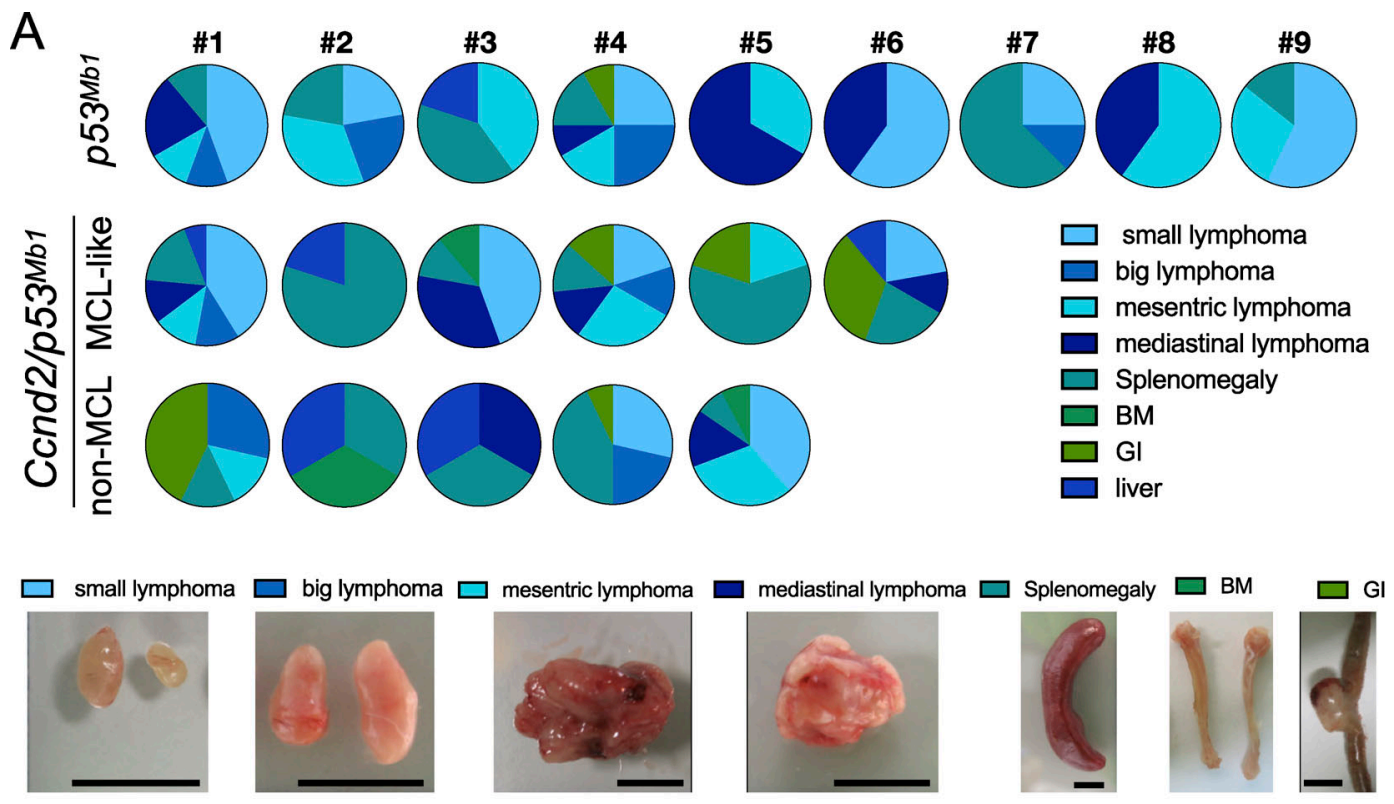

B

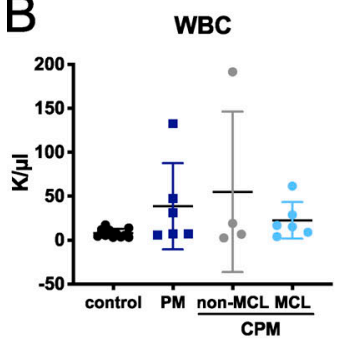

EO

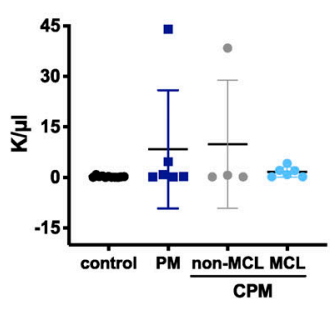

HTC

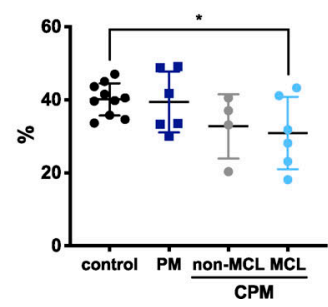

Ly

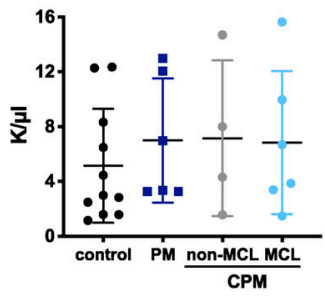

NE

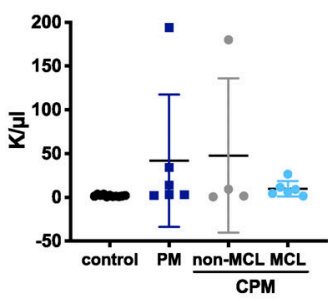

PLT

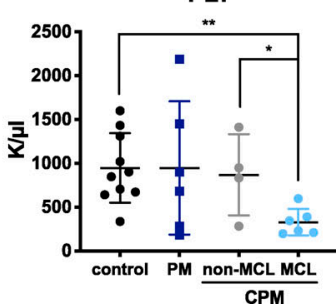

MO
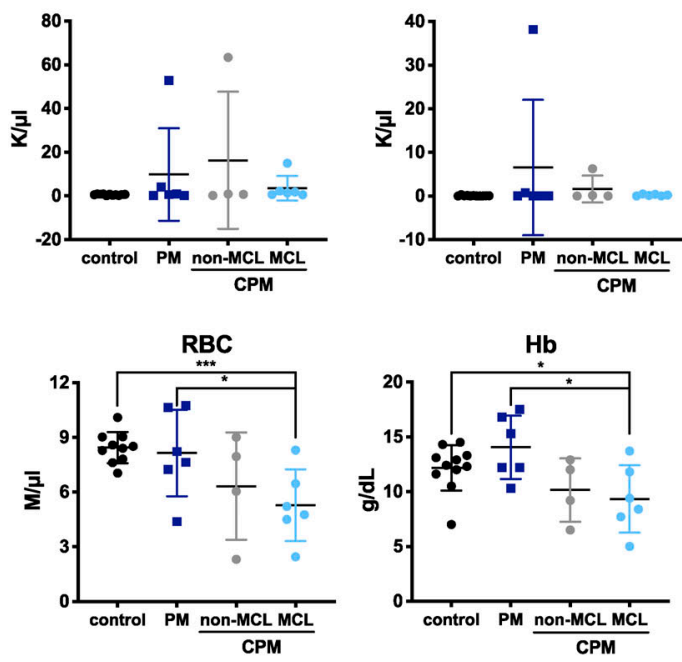

C

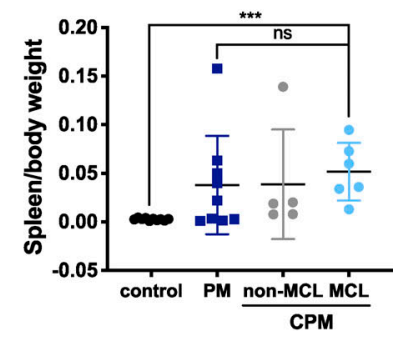

Figure S3. Characterization of tumors from $p 53^{M b 1}$ and $C c n d 2 / p 53^{M b 1}$ mice. (A) Tumor in spectrum in $p 53^{M b 1}$ and non-MCL and $M C L-l i k e ~ C c n d 2 / p 53^{M b 1}$ mice. Pie charts shows the distribution (amount of pie slices) and amount/size (slice thickness) of tumors for each mouse (top). Representative pictures from different lymphadenopathies or tumor-infiltrated organs are shown at the bottom. Gl, gastrointestinal tract. Scale bar, $1 \mathrm{~cm}$. (B) Peripheral blood values of p53 $3^{M b 1}$ (PM), Ccnd2/p53 ${ }^{M b 1}$ (CPM, with or without MCL-like immunophenotype) and Cre-negative control mice. WBC, white blood cells; NE, neutrophils; Ly, lymphocytes; MO, monocytes; EO, eosinophils; BA, basophils; HTC, hematocrit; Hb, hemoglobin b; PTL, platelets. An unpaired t-test indicated that there was a significant difference between $\mathrm{Ccnd2} / \mathrm{p5} 3^{\mathrm{Mbl} 1}(\mathrm{MCL})$ and control mice in their levels of RBC, Hb, HTC, and PLT (***, P $=0.0005 ;{ }^{* *}, \mathrm{P}=0.0075 ;{ }^{*}, \mathrm{P}=0.0221$; and ${ }^{*}, \mathrm{P}=0.0027$, respectively), between $\mathrm{p} 53^{\mathrm{Mb} 1}$ and $\mathrm{C} c n d 2 / \mathrm{p} 53^{\mathrm{Mb1}}(\mathrm{MCL})$ mice in levels of $\mathrm{RBC}$ and $\mathrm{Hb}\left({ }^{*}, \mathrm{P}=0.0464\right.$ and ${ }^{*}, \mathrm{P}=0.0211$, respectively), and between

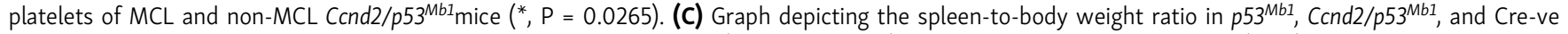
control mice. An unpaired t-test indicated that there was a significant $\left.{ }^{* * *}, \mathrm{P}=0.0001\right)$ difference between $\mathrm{Ccnd2} / \mathrm{p} 53^{\mathrm{Mb1}}(\mathrm{MCL})$ and control mice, but no significant $(\mathrm{P}=0.5625)$ difference between $\mathrm{p} 53^{\mathrm{Mb1}}$ and $\mathrm{Ccnd2} / \mathrm{p} 53^{\mathrm{Mb1}}(\mathrm{MCL})$ mice. Error bars represent SD. 

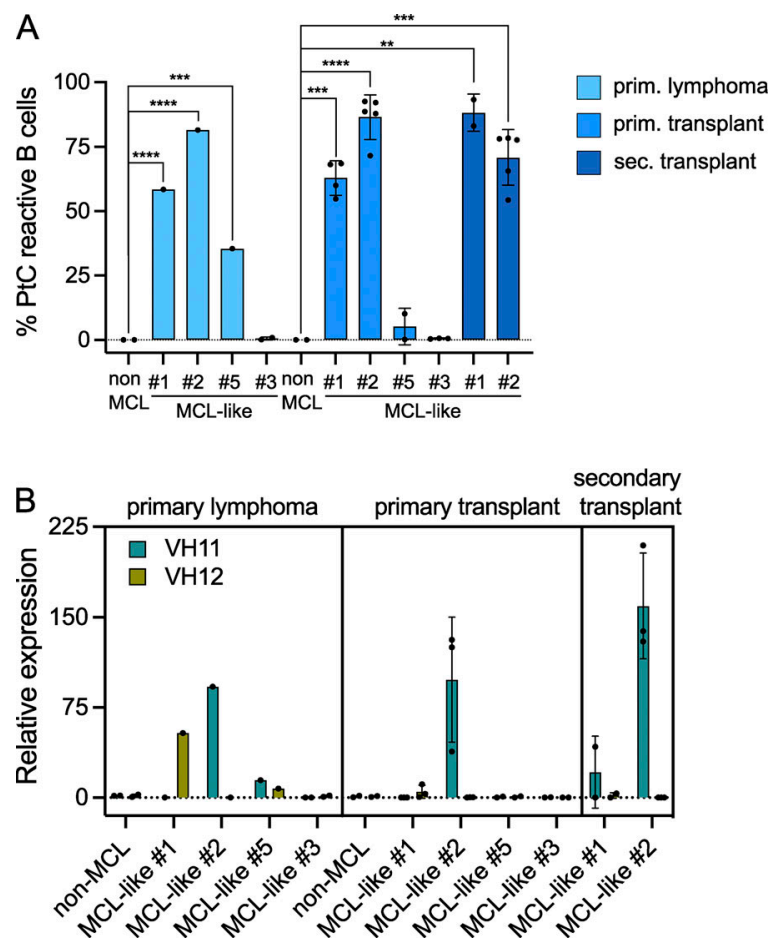

Figure S4. Analysis of B1-specific BCRs in transplanted Ccnd2/p53 ${ }^{\text {Mb1 }}$ lymphomas. (A) Graph depicting the frequency of PtC-reactive B cells (pregated on $\mathrm{CD} 45^{+} \mathrm{CD} 19^{+}$single live $\mathrm{B}$ cells) of primary lymphoma and primary and secondary $\mathrm{C}$ cnd2/p53 ${ }^{\mathrm{Mb1} 1}$ transplants, as determined by flow cytometry. ${ }^{* *}, \mathrm{P}<0.01 ;{ }^{* * *}$, $\mathrm{P}<0.001 ;{ }^{* * * *}, \mathrm{P}<0.0001$. (B) Graph depicting the relative expression of heavy chain variable domains $\mathrm{VH} 11$ and $\mathrm{VH} 12$ in primary lymphoma and in primary and secondary $C \mathrm{cnd} 2 / \mathrm{p} 53^{\mathrm{Mb1}}$ transplants, as determined by qRT-PCR analysis. Error bars represent the SD of independent lymphomas. 
A
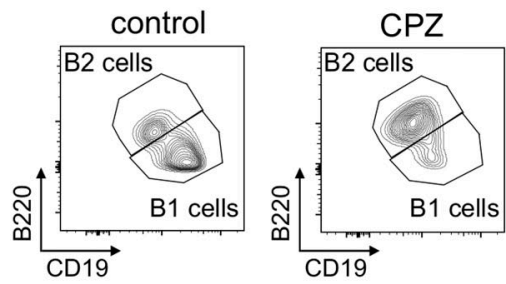

B

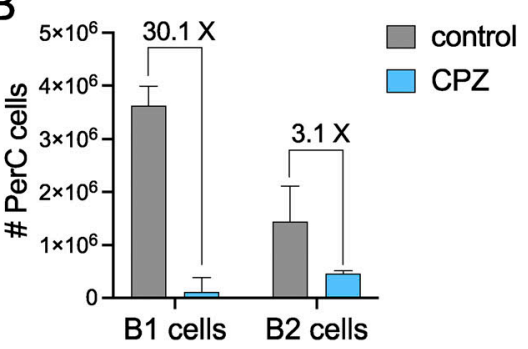

C

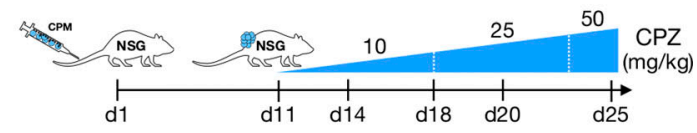

D

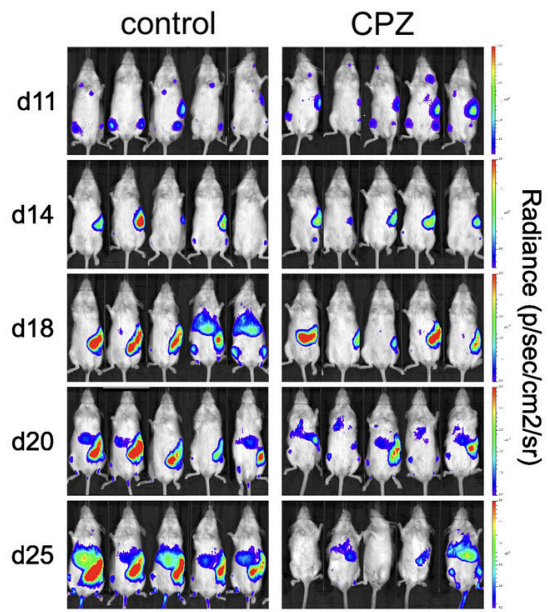

$E$

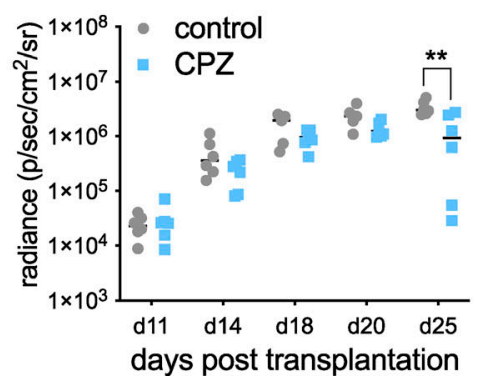

Figure S5. MALT1 inhibitor CPZ reduces B1 cells and B1-derived MCL-like lymphomas in vivo. (A) Flow cytometry analysis for CD19 and B220 on PerC B cells in wild-type mice (three mice/group; mixed C57Bl6/129/Swiss background) that were treated 1 wk with PBS or $10 \mathrm{mg} / \mathrm{kg}$ CPZ. (B) Graph depicting the number of peritoneal B1 and B2 cells in control and CPZ-treated mice $(n=3)$. The fold decrease upon CPZ treatment is indicated. (C) Scheme for intravenous transplantation of a C Cnd2/p53 $3^{M b 1}$ lymphoma with MALT1 activity (MCL-like \#2) in immunocompromised NSG mice and treatment schedule. (D) Bioluminescence over time in NSG mice that were transplanted and treated with either vehicle or CPZ. (E) Quantification of radiance from mice depicted in D. Error bars represent SD. ${ }^{* *}, \mathrm{P}=0.0060 . \mathrm{p} / \mathrm{sec} / \mathrm{cm}^{2} / \mathrm{sr}$, photons per second per square centimeter per steradian.

Provided online are three tables. Table S1 contains a list of single-nucleotide variants and indels from four Ccnd2 ${ }^{\text {vav }}$ lymphomas. Table S2 contains a gene expression signature for $C \mathrm{cnd} 2 / \mathrm{p} 53^{\mathrm{Mb1}}$ lymphomas with or without an MCL-like immunophenotype. Table S3 contains primers for cloning, genotyping, and qRT-PCR, as well as information on antibodies that were used for flow cytometry. 